\title{
Unconventional experimental technologies used for phase change materials (PCM) characterization. Part 2. Morphological and structural characterization, physico-chemical stability and mechanical properties
}

\author{
A. Inés Fernández ${ }^{1}$, Aran Solé ${ }^{2}$, Jessica Giró-Paloma ${ }^{1}$, Mònica Martínez ${ }^{1}$, Mila Hadjieva ${ }^{3}$, \\ Abdel Boudenne ${ }^{4}$, Mariaella Constantinescu ${ }^{5}$, Elena Maria Anghel ${ }^{5}$, Marta Malikova ${ }^{6}$, Igor \\ $\mathrm{Krupa}^{6}$, Conchita Peñalosa ${ }^{7}$, Ana Lázaro ${ }^{7}$, Halime O. Paksoy ${ }^{8}, \mathrm{Kemal} \mathrm{Cellat}^{8}$, Jana Vecstaudža ${ }^{9}$, \\ Diana Bajare ${ }^{9}$, Bostjan Sumiga ${ }^{10}$, Bojana Boh $^{10}$, Thomas Haussmann ${ }^{11}$, Stefan Gschwander ${ }^{11,}$ \\ Robert Weber $^{12}$, Piotr Furmanski ${ }^{13}$, Maciej Jaworski ${ }^{13}$ and Luisa F. Cabeza ${ }^{2}$
}

1. Department of Materials Science \& Metallurgical Engineering, Universitat de Barcelona, Martí i Franqués 1-11, 08028-Barcelona, Spain, Phone: +34-934021298, e-mail: ana_inesfernandez@ub.edu

2. GREA Innovació Concurrent, Universitat de Lleida, Edifici CREA, Pere de Cabrera s/n, 25001-Lleida, Spain, Phone: +34-973 003576, e-mail: Icabeza@diei.udl.cat

3. CCL SENES, Bulgarian Academy of Sciences, 72 Tzarigradsko schosse blvd., 1784 Sofia, Bulgaria, Phone: +359 2 9795959, e-mail: hadjieva@phys.bas.bg

4. CERTES EA 3481 - Centre d'Etude et de Recherche en Thermique, Environnement et Systèmes, Université Paris Est Créteil, 61 av. du Général de Gaulle, 94010 Créteil cedex, France, Phone: +33 145171828, e-mail: fois@u-pec.fr

5 Institute of Physical Chemistry "Ilie Murgulescu" of Romanian Academy, Spl.Independentei 202, 060021 Bucharest, Romania, Phone: +40213167912; e-mail: mariella_const@yahoo.com

6. Polymer Institute, Slovak Academy of Sciences, Dubravska cesta 9, 84545 Bratislava, Slovakia, Phone: +421 23229 4334, e-mail: marta.malikova@savba.sk

7. Aragón Institute for Engineering Research (I3A), Thermal Engineering and Energy Systems Group, University of Zaragoza, Agustín Betancourt Building, C/María de Luna 3, 50018 Zaragoza, Spain Phone: (+34) 976762566, e-mail: ana.lazaro@unizar.es@unizar.es

8. Department of Chemistry, Cukurova University, 01330 Adana, Turkey. Phone: (+90) 3223386418, email: hopaksoy@cu.edu.tr

9. Riga Technical University, Kalku St 1, Riga, 1658 Latvia, Phone: (+371) 67089132, e-mail: diana.bajare@rtu.Iv

10. University of Ljubljana, Faculty of Natural Sciences and Engineering, Askerceva cesta 12, 1000 Ljubljana, Slovenia. Phone: (+386) 12514326, e-mail: bostjansumiga@gmail.com

11. Fraunhofer Institute for Solar Energy Systems, Heidenhofstrasse 2, 79110 Freiburg, Germany, Phone: (+49) 7614588 5351, e-mail:thomas.haussmann@ise.fraunhofer.de

12. EMPA, Building Science and Technology Laboratory, Uberlandstrasse 129, 8600 Dubendorf, Switzerland, Phone: +41 5876543 38, e-mail: Robert.Weber@empa.ch

13. Institute of Heat Engineering, Warsaw University of Technology, Nowowiejska 21-25, 00-665 Warsaw, Poland, Phone: +48 2223452 09, e-mail: maciej.jaworski@itc.pw.edu.pl 


\begin{abstract}
Due to the high interest of appropriate characterization of PCM and hybrid PCM composites, different research centres and universities are using several material characterization techniques not commonly used with PCM, to study the structure and morphology of these materials. Likewise, physico-chemical stability is a crucial parameter for the performance of latent storage materials during time and its evaluation has been done by using molecular spectroscopy, chemiluminiscence or calorimetric tests. Atomic force microscopy and nanoindentation are also reported to characterize hybrid PCM composites. Other chemical aspects studied are related with the compatibility of the PCM and its container and also considered in this compilation of characterization work.
\end{abstract}

Keywords: Phase change material (PCM), characterization, morphological and structural characterization, physico-chemical stability, mechanical properties

\title{
1. Introduction
}

Characterization of PCM and hybrid PCM composites is of great interest for the scientific community, because it is of extreme importance for the deployment of such materials into the market. In a previous paper [1] special attention was paid to the characterization of thermophysical properties showing the difficulties of using commercial equipment with composite materials and/or samples size above few milligrams.

Although the thermopysical properties are the main selection criteria for the use of PCM, other important properties such as chemical stability, crystalline structure or mechanical properties are extremely important to predict the performance of the hybrid PCM composites. This paper includes examples for the analysis of morphological and structural characterization of hybrid PCM composites, physico-chemical stability and mechanical properties.

Characterization of hybrid materials has different approaches depending on the scale (nano- and micro- to bulk and macro-scale). The morphological and structural characterization gives information on crystalline characteristics, and how the microstructure may be affected by cycling the hybrid material. PCM crystalline structure is evaluated with cycles and temperature changes. Matrix structure or even the encapsulating coating materials may be also evaluated in terms of volume expansion while melting, and therefore the change in their mechanical properties. 
Chemical stability of the hybrid materials is also a key issue. Cycling organic materials may lead to a partial degradation that is reflected then in thermal properties. Related with the chemical stability there is the compatibility of the composite, how it is affecting the PCM the matrix properties i.e. chemical, mechanical or even fire resistance properties.

\section{Morphological and structural characterization of hybrid PCM composites}

The morphological and structural characterization of hybrid PCM composites may be carried out using commercial and experimental devices. This paper is focussed in both types, giving examples of the characterization of different PCM and PCM-composites using several experimental procedures.

\subsection{X-Ray Diffraction}

Crystalline structure of organic and inorganic PCM and hybrid PCM composites is studied by X-Ray Diffraction at the Institute of Physical Chemistry Romanian Academy (Romania) [2]. Changes after cycling may be followed by this technique. Moreover, it is possible to calculate the crystallite size, and with additional data the degree of crystallinity and the time of the fastest crystallization. Figure 1 shows an example where the crystalline structure of a polyethylene glycol-epoxy (PEG-epoxy) composite is evaluated.

X-ray diffractograms were collected by means of a Rigaku diffractoctomer type Ultima IV in parallel-beam geometry. The X-ray from a $\mathrm{Cu}$ tube operating at $40 \mathrm{kV}$ and $30 \mathrm{~mA}$. Counts were collected from $5^{0}$ to $60^{0}$ with a step size of 0.02 and a speed of $5^{0} / \mathrm{min}$. It was assumed that the main contributor to the peak broadening is the finite size of the PEG chains.

\subsection{Optical and thermal microscopies}

The optical microscopy is used at the Bulgarian Academy of Sciences (Bulgaria) to control crystal formation, size, allocation, and modification before and after thermal cycling in PCM slurries. An example can be seen in Figure 2, where two morphological photos compared are of Clathrate hydrate slurry.

"In situ" control during thermal cycling of PCM can be carried out with a thermal microscope (Bulgarian Academy of Sciences - Bulgaria) (Figure 3). LINKAM Scientific Instruments THMS600 provided with T95-Linksys PC interface and Linksys 32X system controller software, enabling PC control of temperature stability $<0.1^{\circ} \mathrm{C}$, gas flow (linear cooling speeds 
from 0.01 to $100^{\circ} \mathrm{C} / \mathrm{min}$ ), data acquisition and export, as well as multiple rise/down programming. The sample area is $22 \mathrm{~mm}$ diameter. A $100 \mathrm{Ohm}$ platinum resistor sensor makes available more accurate and stable temperature signal that can be achieved with a thermocouple. PixeLINK application software we use for digital image capture of the PCM slurry or PCM composite morphology in parallel to their thermal behaviour:

- Temperature range of phase transition, Tonset, Tmax compared to DSC data.

- Crystallization/nucleation phenomena in situ.

- Stability of interfacial surfactant molecular layer in PCM emulsion slurry.

- Droplet size, shape, distribution.

- Temperature effect on the salt adhesion process in the graphite/Al matrix.

\subsection{Scanning electron microscopy}

Scanning electron microscopy is a useful tool to evaluate morphological characteristics of PCM and PCM composites at the microscale. It has been used by CERTES - France \& Polymer Institute (France) and the Slovak Academy of Sciences (Slovakia) to evaluate PCM particles shape, the quality of the silver coating PCM and also the dispersion of fillers inside the polymeric matrix. SEM (Jeol 6301F) fitted with an X-ray energy dispersive spectrometer (EDS, Oxford, Link Isis) was used and SEM images like the one presented in Figure 4 were taken at $0^{\circ}$ tilt angle, using a $10-15 \mathrm{kV}$ accelerating voltage. The samples (PCM particles and PCM particles metalized with silver and composites) were covered previously with a thin layer of gold to guarantee their electrical conductivity in order to prevent drift and charging.

At Riga Technical University (Latvia), a simple method was used for preparing samples for determination of the shell thickness of PCM microcapsules. The slurry of microcapsules was dried in the open air. The dried specimen was broken and fracture was exposed to SEM observation (Figure 5). Riga Technical University also used SEM to investigate damage resistance of microcapsules in the cement-lime mixtures before and after thermal cycling. For example, Figure 6 shows that the microcapsules were not damaged by the mixing procedure of mortar and cycling for 300 times in the temperature range from +5 to $45^{\circ} \mathrm{C}$ [4].

\subsection{Atomic Force Microscopy}

At the Institute of Physical Chemistry Romanian Academy (Romania), in the study of PEG composites, AFM is used to evaluate the surface morphology of the P15-E. AFM Dynamic Force Module (intermittent contact mode), using an EasyScan 2 apparatus (Nanosurf AG, Switzerland) with a high resolution scanner (10 x $10 \mu \mathrm{m}$ with vertical range of $2 \mu \mathrm{m}$ and $\mathrm{z}$-axis 
resolution of $0.027 \mathrm{~nm}$ ) and a X-Y linearity mean error less than $0.6 \%$. The scan rate was about 1-2 Hz. The phase contrast working mode for imaging employed sharp Si tips (NCLR from Nanosensors ${ }^{\mathrm{TM}}$ ) with a radius of curvature less than $10 \mathrm{~nm}$ (typically $7 \mathrm{~nm}$ ).

The $1.5 \times 1.5 \mu \mathrm{m}$ phase image of the P15-E in the Figure 7 shows a lamellar morphology with an interlamellar spacing of $55 \mathrm{~nm}$. The XRD calculation of the d-spacing for the 120 reflection shows is tantamount to $0.52784 \mathrm{~nm}$.

At the University of Barcelona (Spain) AFM is used to evaluate the morphology and mechanical integrity of microencapsulated PCM with temperature [5]. The aim of this study is to evaluate the mechanical performance of microencapsulated Micronal ${ }^{\circledR}$ DS 5001 provided by $\mathrm{BASF}^{\circledR}$ at different temperatures of use: $25{ }^{\circ} \mathrm{C}, 45{ }^{\circ} \mathrm{C}$ and $80{ }^{\circ} \mathrm{C}$, approximately. When microencapsulated PCM is used as aqueous slurry in active storage systems, changes are observed after several thermal cycles that are attributed to a partial degradation of the microcapsules by breakage. For this reason, it is interesting to measure the maximum force these particles can hold before break.

Observation of Micronal particles with SEM reveals that small particles (6 $\mu \mathrm{m}$ diameter) aggregate in bigger particles around $150 \mu \mathrm{m}$ ). Both types of particles were indented with the cantilever using the following experimental conditions:

- Aggregates $(100 \mathrm{M}) 150 \mu \mathrm{m} \quad \mathrm{F}=3 \mu \mathrm{N}$

- Single particles $(10 \mathrm{M}) 6 \mu \mathrm{m} \quad \mathrm{F}=1.5 \mu \mathrm{N}$

In Figure 8 results of the several indentations are represented statistically as the frequency of each outcome for aggregates and individual Micronal particles at different temperatures.

\subsection{Molecular spectroscopies}

Raman spectroscopy is a very useful technique in studying chemical structure and morphology of heterogeneous materials as the PEG composites. At the Institute Physical Chemistry of the Romanian Academy (Romania) unpollarized Raman spectra of the P15-E composite at room temperature were obtained on a Jasco NRS-3300 micro-Raman spectrometer with an air cooled detector in a Backscattering geometry using a microscope objective of 100x. Two excitation laser lines, operating at 488 and $785 \mathrm{~nm}$, were used with the power at the sample surface of 12.3 and $5.2 \mathrm{~mW}$, respectively. Spectra were recorded in a single subtractive configuration (gratings $1800 \mathrm{gr} / \mathrm{mm}$ and $600 \mathrm{l} / \mathrm{mm}$ ) over a wide frequency range of $100-4000 \mathrm{~cm}^{-1}$ for $\mathrm{Ar}^{+}$-ion laser and $100-1800 \mathrm{~cm}^{-1}$ for diode laser. The fluorescent background for each spectrum of the P15-E 
composite was subtracted by using linear segments. All corrected Raman spectra were fitted with Lorenzian profiles by means of Igor software. Unpolarized Raman spectrum of the P15-E composite and its spectral deconvolution is shown in Figure 9 [6].

Unpolarized solid state Raman spectra were recorded over $10-900 \mathrm{~cm}^{-1}$ and $200-1800 \mathrm{~cm}^{-1}$ using a RM-1000 RENISHAW Raman Microscope, equipped with a charge coupled device (CCD) detector, and a Leica microscope with a 50x objective, in backscattering geometry. The emission line at $514.532 \mathrm{~nm}$ of an $\mathrm{Ar}^{+}$laser was used to excite the samples. The diameter of the laser spot on the sample surface amounted to 2-3 $\mu$ m providing a spectral resolution better than $2 \mathrm{~cm}^{-1}$. A THMS-600 cell (LINKAM) was used for temperature control of the samples from 25$600^{\circ} \mathrm{C}$ with an accuracy of the $0.1^{\circ} \mathrm{C}$. Raman spectra collected at different temperatures were temperature-reduced to account the first order Bose-Einstein distribution factor from the experimental spectra. As is shown in Figure 10, the images and band at $2500-3500 \mathrm{~cm}^{-1}$ indicate the influence of temperature at the phase change by cycling.

At the University of Barcelona (Spain) Fourier Transformed Infrared Spectroscopy (FT-IR) with an ATR accessory was used to characterise wood-PCM composites prepared at Riga Technical University (Latvia) [7]. In this study, black alder wood (Alnus Glutinosa) was impregnated with paraffins RT21 and RT27 - PCMs manufactured from Rubitherm GmbH. Samples were also coated with a polystyrene based coating to avoid leakage. Introduction of PCM in wooden matrix gives rise to absorption bands in the wavenumber region of $3000-2800$ $\mathrm{cm}^{-1}$. These bands correspond to methyl and methylene group stretching, as RT21 and RT27 are saturated hydrocarbons with molecular formula $\mathrm{C}_{\mathrm{n}} \mathrm{H}_{2 \mathrm{n}+2}$. Wood adds characteristic absorption bands of cellulose, hemicellulose and lignin to the wood/PCM composite spectra. Bands of polystyrene usually appear of composite layers closer to surface or ends of the sample. Homogeneity of impregnated PCM was evaluated by comparing spectra of wood/PCM composite cut in several slices. Differences between slices of one sample are illustrated in Figure 11.

At Çukurova University (Turkey), PCM samples are subjected to melting/freezing thermal cycles carried out to determine their thermal and chemical stability. The number of thermal cycles varies depending on the application of PCM. FTIR analysis is used to test the chemical stability. The basic approach is to carry out FTIR analysis before and after thermal cycling and to compare the characteristic peaks obtained in the spectra. Figure 12 shows FT-IR spectra of the non-cycled and cycled (200, 400, 600 cycles) Capric acid-Myristic acid (CA-MA) binary mixture as PCM [8]. As seen in the figure, all peaks fit into one another at the same frequency 
band. This means that repeated thermal cycles did not cause any degradation in the chemical structure of PCM the mixture.

\section{Physico-chemical Stability}

\subsection{Chemiluminiscence}

Chemiluminiscence results from the conversion of chemical energy into light which takes place in many elementary reactions of more complex reaction mechanisms. During oxidation the molecules of a reaction product which are formed in an excited state are either carbonyl compounds or singlet oxygen. These products are formed during recombination of peroxy radicals.

The equipment unifies knowledge acquired in the study of chemiluminescence of organic substrates since 1960 by groups of researchers in Australia, Russia, United Kingdom, USA and the former Czechoslovakia (Polymer Institute of Slovak Academy of Sciences). It is suitable for the detection and measuring of thermal oxidation of polymers or thermal decomposition of preoxidized polymers containing hydroperoxides from ambient temperature to $240{ }^{\circ} \mathrm{C}$. The standard atmosphere is ensured by flow of gas at maximum rate of $150 \mathrm{ml} / \mathrm{min}$. Extreme sensitivity, which is achieved by almost zero background noise, enables to measure the oxidation of polymers already at $40{ }^{\circ} \mathrm{C}$ and the tendency towards oxidation of organic substrates even in the so-called "induction period" may be well estimated.

The final form for the chemiluminescence intensity is expressed as the sum of two processes composing the resulting light emission. The degradation of the PEG composites developed at the Institute Physical Chemistry of the Romanian Academy (Romania) [6], was studied and the two processes are related to the rate of initiation of polyethylene glycol (PEG) degradation via pre-exponential factors and activation energies. All the kinetic parameters, i.e. pre-exponential factor, activation energy, and average kinetic rate, are calculated for $150{ }^{\circ} \mathrm{C}$. Modelling of the kinetics is shown in Figure 13.

\subsection{Chemical stability related to fire testing}

For testing of PEG-epoxy composite P15-E, a modified set up in comparison to the ASTM E84 Standard Test Method for Surface Burning Characteristics of Building Materials was used at the Institute of Physical Chemistry of the Romanian Academy (Romania), where a reduced size specimen with $150 \mathrm{~mm}$ long, $75 \mathrm{~mm}$ wide and $25 \mathrm{~mm}$ thick was placed between two plaster 
sheets of $125 \mathrm{~mm}$ thickness. To avoid direct contact of the fire with the sample the two plaster panels were $20 \mathrm{~mm}$ longer than the rectangular specimen, as is shown in Figure 14 left. Thus, indirect slow heating at the bottom side of the material cuboid was used. The temperature on both sides of the sample was monitored by means of two K thermocouples in time (Figure 14 right). The bottom side temperature of the specimen did not exceed $100^{\circ} \mathrm{C}$ during the 20 minute span of the test in order to monitor the thermal degradation of the PCM component, i.e. PEG 1500, leaving unaffected the thermosetting component (the cured epoxy resin) prone to degradation at higher temperatures.

Degradation of PCM composites after the fire testing was evaluated using FTIR with coupled ATR Spectra of the FP15-E and RP15-E samples along with their Gaussian deconvolutions within $1200-975 \mathrm{~cm}^{-1}$ and $3700-2600 \mathrm{~cm}^{-1}$ ranges. The least varying peak at $1467 \mathrm{~cm}^{-1}\left(\mathrm{CH}_{2}\right.$ deformation) was chosen for spectra normalization of the spectra. The IR spectra emphasize these changes produced inside the material.

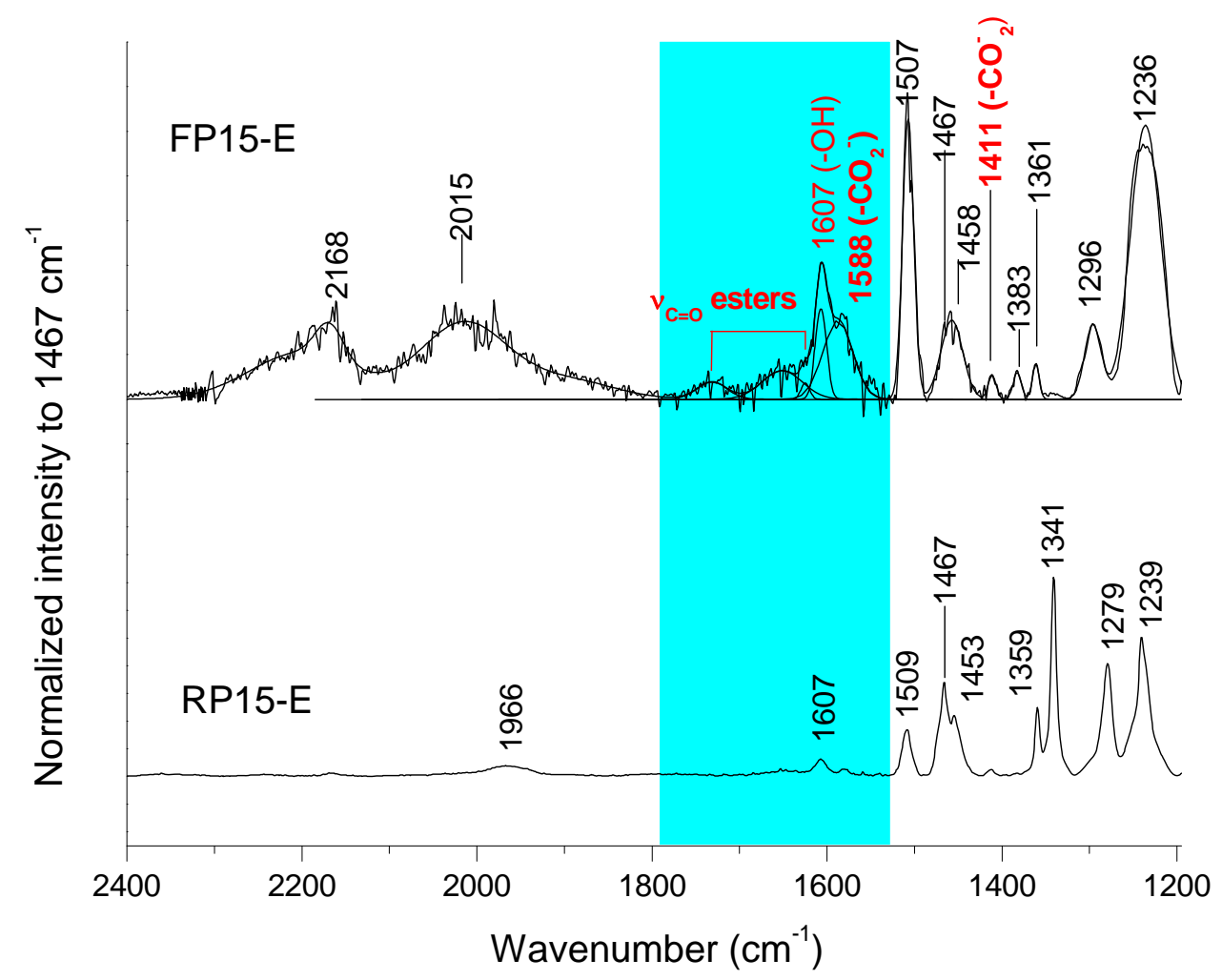

Figure shows the Gaussian deconvoluted IR spectra of the RP15-E and FP15-E samples in the $1200-2400 \mathrm{~cm}^{-1}$ range, where the peaks of ester groups appear after the fire testing, that can be attributed to the thermo-oxidative degradation of the PEG.

\subsection{Compatibility between PCM and container materials}


Chemical compatibility between the PCM, the shape stabilized PCM, PCM slurries and the materials containing them are usually carried out following protocols of corrosion tests (for example, at the University of Lleida and the University of Zaragoza, Spain). For inorganic PCM corrosion of metallic containers is given as a rate of corrosion. Results on this can be found in Cabeza et al. and Oró et al. [9-13]. Otherwise when plastic containers are considered, migration of PCM within the container and water sorption through the plastic wall is usually evaluated by gravimetric analysis after cycling the PCM. Lázaro et al. [14], Castellón et al. [15], and Oró et al. [13] reported some studies of compatibility of plastics with PCM.

The methodology used includes that once the samples were weighted, they were immersed inside glass test tubes containing the PCM formulations. Then, the glass tubes were covered with plastic paraffin to avoid contact with environmental agents. The evolution of corrosion rate in time was evaluated. Visual evaluation was done seeking for bubbles, precipitates, surface changes and pitting process. $\mathrm{pH}$ measurements with litmus paper were also carried out. Before re-weighted, samples were cleaned and dried. While the metal samples were polished with abrasive paper and then dried, the polymer samples were cleaned with soft paper and dried with compressed air.

Results of compatibility of PCM with metals are given on a manufacturers recommendation (Table 1) and are shown in Table 2. Figure 16 shows some samples after the experimentation.

On the other hand, in order to evaluate the polymeric materials, mass change $\Delta \mathrm{m}(\%)$ was calculated. The mass changes could be positive or negative, depending if the polymer absorbs or is diluted by the PCM, respectively.

Results show that polymers here analysed presented no significant mass gain (Table 3). Hence, those materials are suitable and recommended to be used as PCM container with the PCM studied in these papers. Polymers are materials commonly used as containers in other application due to their low price, low density and easy shaping.

\subsection{Rheological behaviour}

A TA Instruments AR-G2 device (a controlled stress rheometer) is used at the University of Zaragoza (Spain) to study the rheological behaviour of the materials [16]. Depending on the objective, different studies can be developed. For those materials that will be pumped in real applications, the viscosity vs. share rates and the viscosity vs. temperature curves are obtained. For those materials that will remain at rest, viscosity vs. temperature curves are obtained with 
share rates close to zero. These last measurements can be complemented with measurements made in oscillatory mode. Figure 17 shows examples of these results obtained for octadecane at the University of Zaragoza.

\subsection{Thermal stability investigation}

A calorimeter was designed at the Warsaw University of Technology (Poland) for the performance of fast melting and solidification (cycling) of phase change materials and investigation of the stability of their thermophysical properties [17]. Since the volume of sample container equals to $200 \mathrm{~cm}^{3}$, results are representative for real elements with PCM which are used in thermal storage units. Temperature range is limited to $20-150^{\circ} \mathrm{C}$, mainly because the cooling system used in the set-up.

The scheme of the main part of the calorimeter is shown in Figure 18, and it is used to test the thermal stability of PCM.

Cycling tests consists of two consecutive phases, which are repeated from several to several hundred times, depending of the thermal behaviour of the material. In order to check whether material is stable or not, temporal temperature variations during melting and solidification are recorded and analysed. In Figure 19 temperature vs. time for selected cycles of the tests performed on the hydrate $\mathrm{Na}_{2} \mathrm{~S}_{2} \mathrm{O}_{3} \cdot 5 \mathrm{H}_{2} \mathrm{O}$ are presented. Since the temperature characteristics change substantially in subsequent cycles, this material is not stable. In $28^{\text {th }}$ cycle melting is not observed, that means that the hydrate decomposed into the salt and water. If material is stable all recorded characteristics look very similar to that for the first cycle.

\subsection{Physical stability testing of slurries}

Microencapsulated paraffin based phase change slurry (PCS) from BASF has been characterized at the Fraunhofer Institute for Solar Energy Systems (Germany). The initial slurry containing $40 \% \mathrm{wt}$. of capsules was diluted to a capsule fraction of $20 \% \mathrm{wt}$. by adding water. As the density between microencapsulates and water is different, a thickener was added to slow down the separation speed. The enthalpy measured by Micro DSC III from Setaram reveals a melting range between 16 and $18.5^{\circ} \mathrm{C}$, a melting enthalpy of about $40 \mathrm{~kJ} / \mathrm{K}$ and a hysteresis for the solidification curve of $2 \mathrm{~K}$.

After characterization the PCS was tested with a storage test facility. It contains plate type heat exchangers, centrifugal pumps, a $500 \mathrm{~L}$ storage tank and sensors to measure all relevant volume 
flows and temperatures (Figure 20). The heat which is transferred over the heat exchanger from water into the PCS is stored in the tank. Therefore, the volume flow rate through and the temperature difference over the heat exchanger on the thermostat side (red in the schematic drawing - Figure 20) was measured. The heat losses of the storage have been determined with previous experiments using water instead of PCS. For the measurements the storage is operated in different temperature intervals. In the first experiment the intervals have been kept always at $2 \mathrm{~K}$ and the temperature level was increased in $2 \mathrm{~K}$ steps starting from $12{ }^{\circ} \mathrm{C}$ (Figure 21 left). In a second experiment the temperature intervals have been increased from $2 \mathrm{~K}$ to $6 \mathrm{~K}$ and the stored heat was compared with that reached by using water within the same temperature intervals (Figure 21 right).

\section{Mechanical properties}

\subsection{Mechanical characterization at nanometric scale}

The grid indentation technique has been employed to isolate the mechanical properties of a composite material or graphite foam and salt at the University of Barcelona (Spain) in collaboration with TREFFLE laboratory (France). This technique is a powerful tool for examining the properties of constituent phases independently of each other in composite material microstructures without the need to observe the residual imprints. Moreover, the mechanical properties (hardness and Young's modulus) for individual phases can be isolated, as well as their surface volume fractions at nanometric scale. This technique and the statistical analysis by the deconvolution process allow representing the mechanical properties for each phase as a normal density function [18]. It can also be employed to other composite materials containing mixture of constituent phases distributed randomly. In Figure 22 is represented the Young's modulus distribution simulated using the CDF fitting parameters. To complete the mechanical characterization, a macro structure mechanical characterization like micro compression tests must be done.

\subsection{Loss of mechanical properties of polymers in contact with paraffin. Evaluation using nanoindentation}


Nanoindentation technique is adequate to evaluate mechanical changes in the surface and in the internal properties of polymers when exposed to paraffin for a long time. Moreover, the variation of the mechanical parameter with depth of indentation gives also valuable information that may be suitable for design purposes. In this study, carried out at the University of Barcelona (Spain) [19], polypropylene PP unfilled and filled with $\mathrm{Mg}(\mathrm{OH})_{2}$ (40 phr) were submerged in melted paraffin Rubitherm ${ }^{\circledR}$ : RT-25 at different temperatures for 32 days. Stiffness and hardness of polypropylene decreases due to contact with paraffin, and the effect is more significant with increasing temperature. Table 4 summarises some of the results.

\section{Conclusions}

This paper presents different methods to characterize structural and morphological properties of PCM. Molecular spectroscopy, chemiluminiscence and calorimetric test have been presented to study the physico-chemical stability of PCM and hybrid PCM. Atomic force microscopy and nanoindentation are also reported to characterize hybrid PCM composites. Other chemical aspects studied are related with the compatibility of the PCM and its container and also considered in this compilation of characterization work.

The laboratories authoring this paper have participated in the European COST Action TU0802, developing a stable network of scientists that today exchange not only samples to be characterized, but also students and researchers to potentiate the research carried out.

\section{Acknowledgements}

The work is partially funded by the European Union (COST Action COST TU0802) and the Spanish government (ENE2011-28269-C03-01, ENE2011-28269-C03-02 and ENE201122722). The authors would like to thank the Catalan Government for the quality accreditation given to their research group GREA (2014 SGR 123) and their research group DIOPMA (2014 SGR 1543). Aran Solé would like to thank the Departament d'Universitats, Recerca i Societat de la Informació de la Generalitat de Catalunya for her research fellowship.

\section{References}

1. Cabeza L.F, Barreneche C, Martorell I, Miró L, Sari-Bey S, Fois M, Paksoy H.O, Sahan N, Weber R, Constantinescu M, Anghel E.M, Malikova M, Krupa I, Delgado M, Dolado P, Furmanski P, Jaworski M, Haussmann T, Gschwander S, Fernández A.I. Unconventional 
technologies available for phase change materials (PCM) characterization. Part 1. Thermophysical properties. 2014 In press.

2. Constantinescu M, Anghel EM, Constantinescu D, Dumitrache L, Stoica A, Popa VT. Testing Methods for Characterization of New Materials PCM-Epoxy to be used in Buildings. Proceedings of Romphyschem 2010, Bucharest (Romania).

3. Cecen V, Boudenne A, Ibos L, Novák I, Nógellová A, Prokeš J, Krupa I. Electrical, mechanical and adhesive properties of ethylene-vinylacetate copolymer (EVA) filled with wollastonite fibers coated by silver. European Polymer Journal 2008;44(11):3827-34.

4. Bajare D., Kazjonovs J., Korjakins A., Merijs-Meri R., Development of cement and lime based plaster with microencapsulated Phase Change Materials (PCM), The 12th International Conference on Energy Storage, Innostock 2012, Lleida May 15-18, 2012

5. Giro-Paloma J, Oncins G, Martínez M, Xuriguera H, Chimenos JM, Fernández AI. Stiffness characterization of microencapsulated phase change materials by atomic force microscopy. Proceedings of BCNano'11, Barcelona (Spain), 2011.

6. Constantinescu M, Dumitrache L, Constantinescu D, Anghel EM, Popa T, Stoica A, Olteanu M. Latent heat nano composite building materials. European Polymer Journal 2010;46(12):2247-54.

7. Vecstaudza J., Locs J., Bajare D., Barreneche C., Fernández A. I. Characterization of wood/PCM composites for building applications. 2nd International Conference on Sustainable Energy Storage, June 19-21, Trinity College Dublin, Ireland.

8. Cellat K., Varkal I., Paksoy H.O., Güngör C., Konuklu Y., Karahan O., Dündar C. Enhancing Thermal Properties of Concrete Mixtures with Phase Change Materials, 2nd International Conference on Sustainable Energy Storage in Buildings, 19-21 June, 2013, Dublin, Ireland.

9. Cabeza LF, Illa J, Roca J, Badia F, Mehling H. Immersion corrosion tests on metal-salt hydrate pairs used for latent heat storage in the 32 to $36^{\circ} \mathrm{C}$ temperature range. Materials and corrosion 2011;52:140-6.

10. Cabeza LF, Illa J, Roca J, Badia F, Mehling H, Hiebler S, Ziegler F. Middle term immersion corrosion tests on metal salt hydrate pairs used for latent heat storage in the 32 to $36^{\circ} \mathrm{C}$ temperature range. Materials and corrosion 2001;52:748-54.

11. Cabeza LF, Roca J, Nogués M, Mehling H, Hiebler .Immersion corrosion tests on metal-salt hydrate pairs used for latent heat storage in the 48 to $58^{\circ} \mathrm{C}$ temperature range. Materials and corrosion 2002;53:902-7.

12. Cabeza LF, Roca J, Nogués M, Mehling H, Hiebler S, Ziegler F. Long term immersion test son metal-PCM pairs used for latent heat storage in the 24 to $29{ }^{\circ} \mathrm{C}$ temperature range. Materials and corrosion 2005;56(1):33-8. 
13. Oró E, Miró L, Barreneche C, Martorell I, Farid MM, Cabeza LF. Corrosion of metal and polymer container for use in PCM cold storage. Applied energy 2013;109:449-53.

14. Lázaro A, Zalba B, Bobi M, Castellón C, Cabeza LF. Experimental study on phase change materials and plastics compatibility. AICHE Journal 2006;52:804-6.

15. Castellón C, Martorell I, Cabeza LF, Fernández AI, Manich AM. Compatibility of plastic with pahse change materials (PCM). International Journal of Energy Research 2011;35:66571.

16. Delgado M, Gschwander S, Lázaro A, Peñalosa C, Zalba B. Determining the rheological behavior of octadecane as phase change material: First approach. Thermochimica Acta 2012;548:81-7.

17. Domanski R, Jaworski M. Measurements of thermal properties of PCM materials. Proceedings of the 6th International Conference on Thermal Energy Storage Calorstock'94. Espoo, Finland, 1994, pp. 487-494.

18. Canseco V, Roa JJ, Rayón E, Fernández AI, Palomo E. Mechanical characterization at nanometric scale for heterogeneous graphite-salt phase change materials with a statistical approach. Ceramics International 2012;38:401-9.

19. Giró-Paloma J, Fernández AI, Roa JJ, Rayón E, Martínez M. Characterisation of thermoplastics with nanoindentation. Proceedings of the Multiphase Polymers and Polymer Composites from Nanoscale to Macro Composites, Paris (France), 2011. 
Figure captions

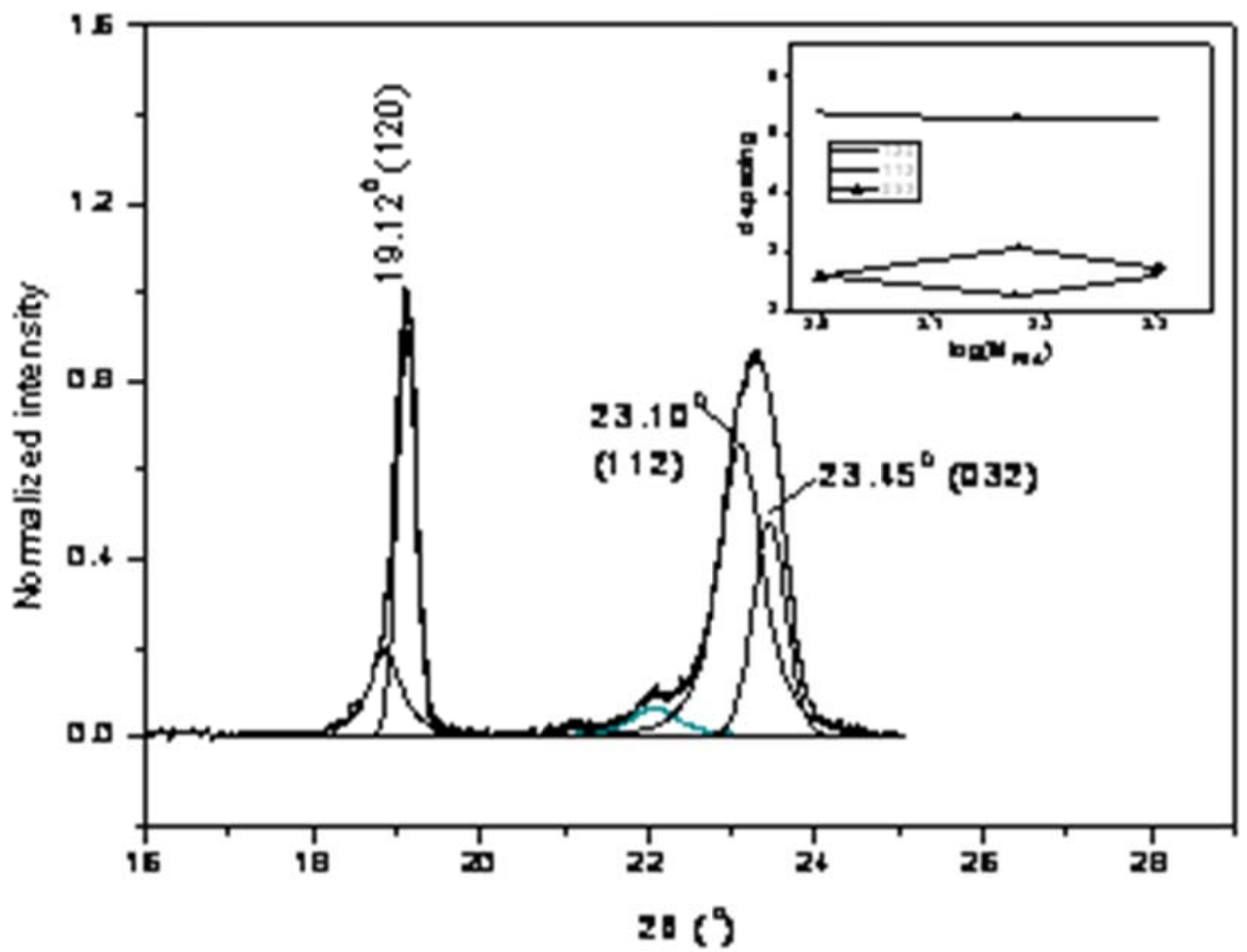

Figure 1. Fitted XRD diffractogram of the P15-E composite within $17-25^{\circ}(2 \theta)$. In the inset the d-spacing of the $\mathrm{P}(10 / 15 / 20)$-E composites was illustrated versus log of the molecular weights of the PEGs [2].

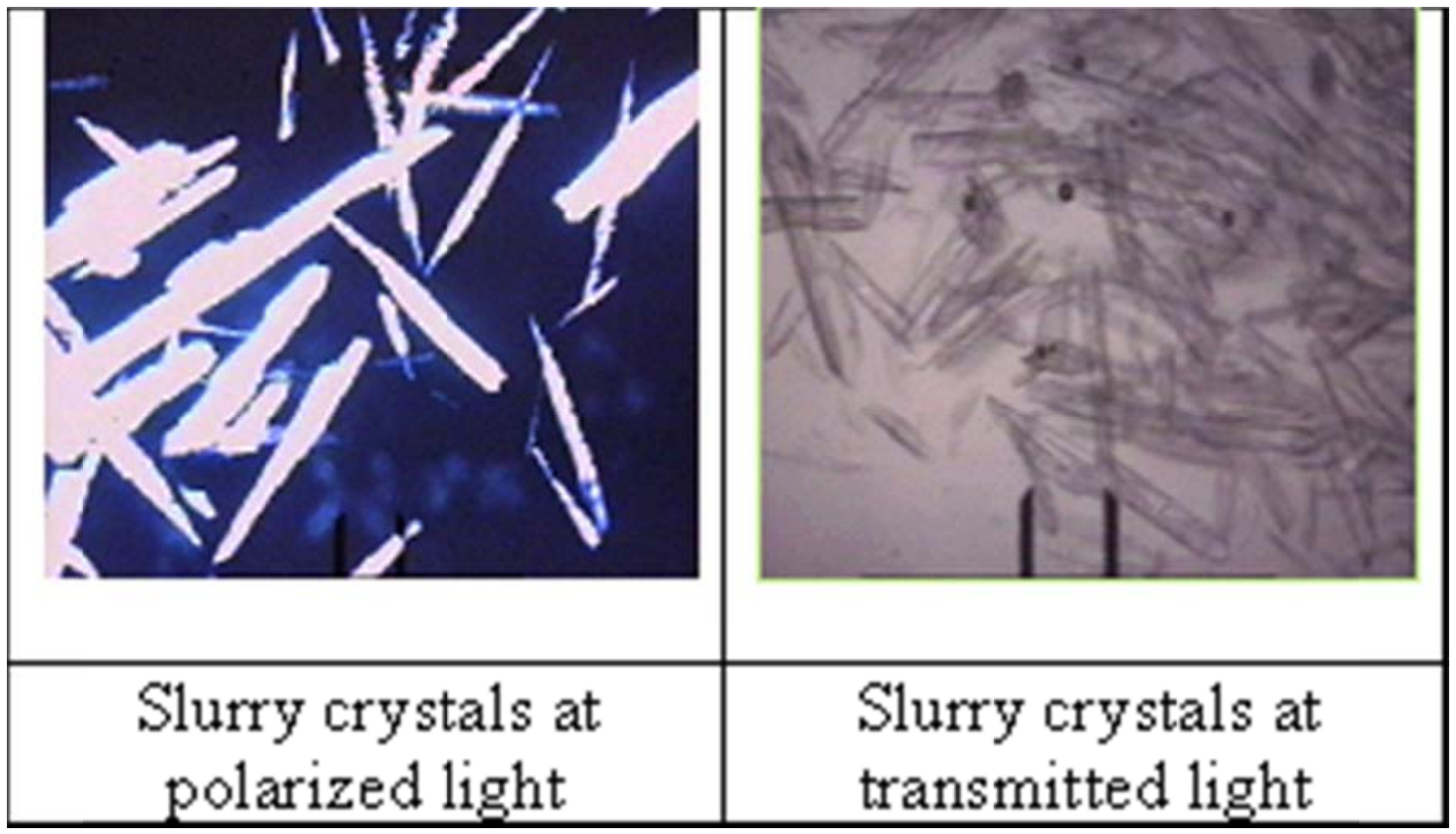

Figure 2. Optical microscope control on the clathrate crystallization process 


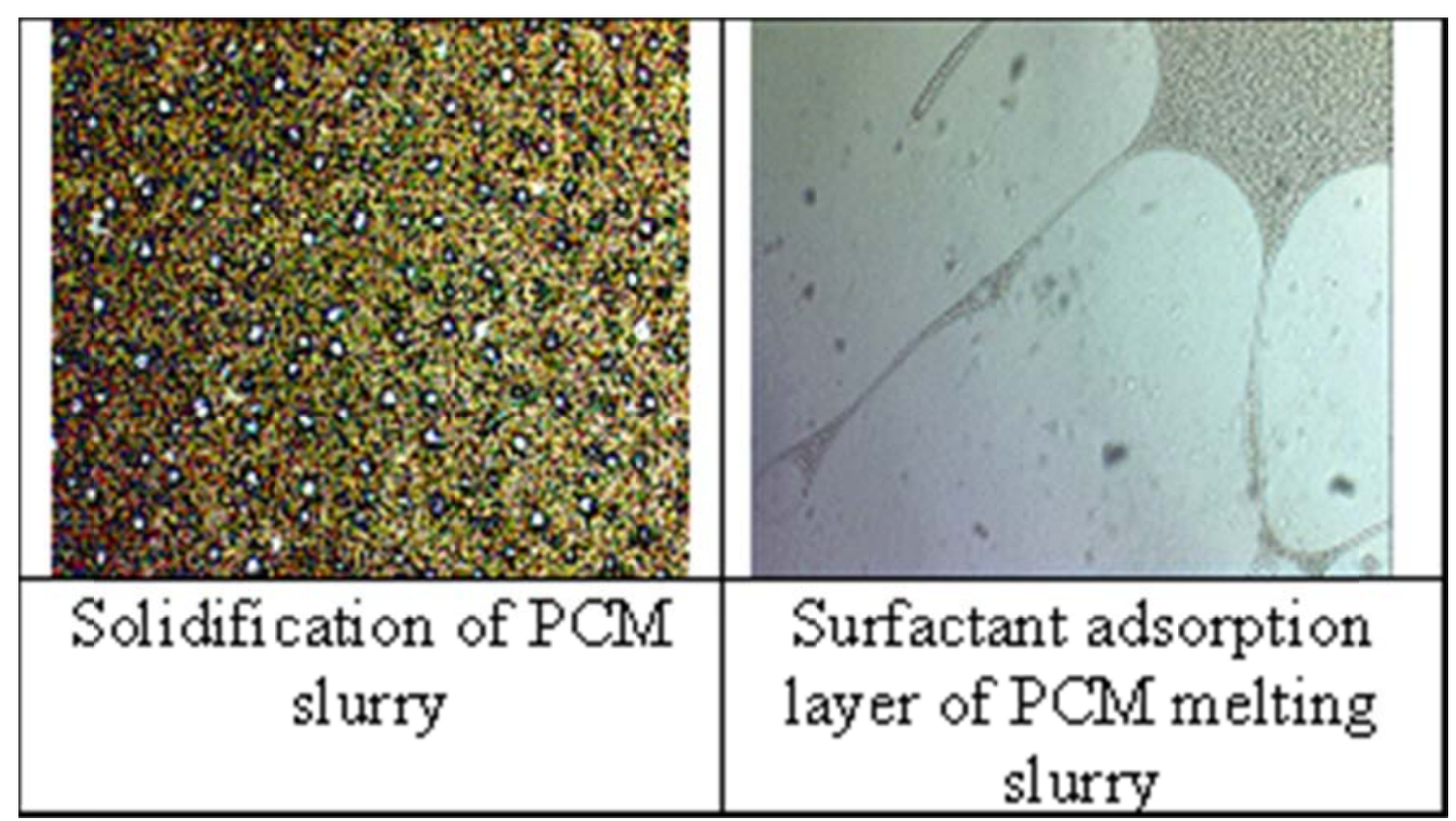

Figure 3. LINKAM thermal microscopy control on multiple phase transition of paraffin slurry.

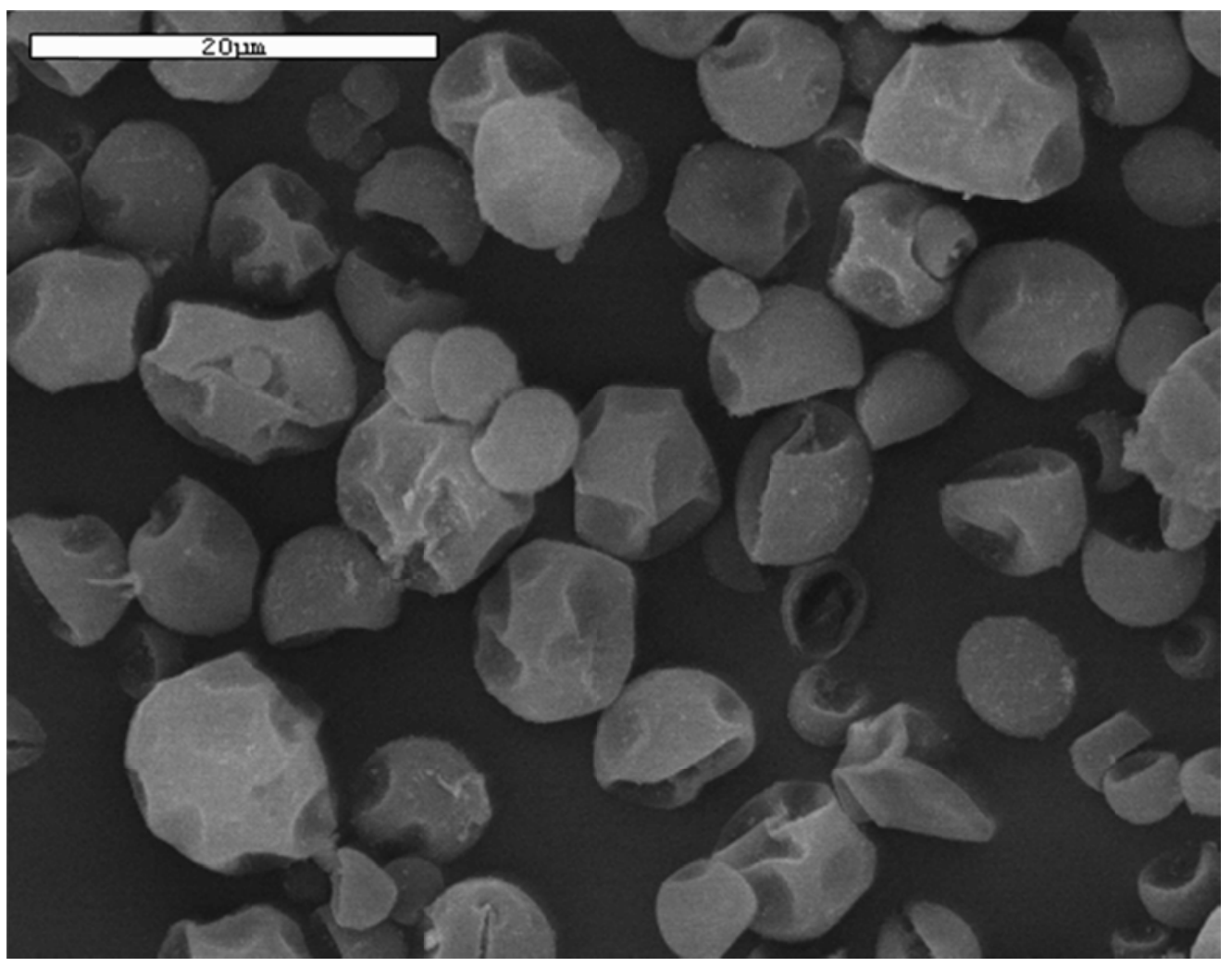

Figure 4. SEM image of PCM particles metalized with silver [3]. 


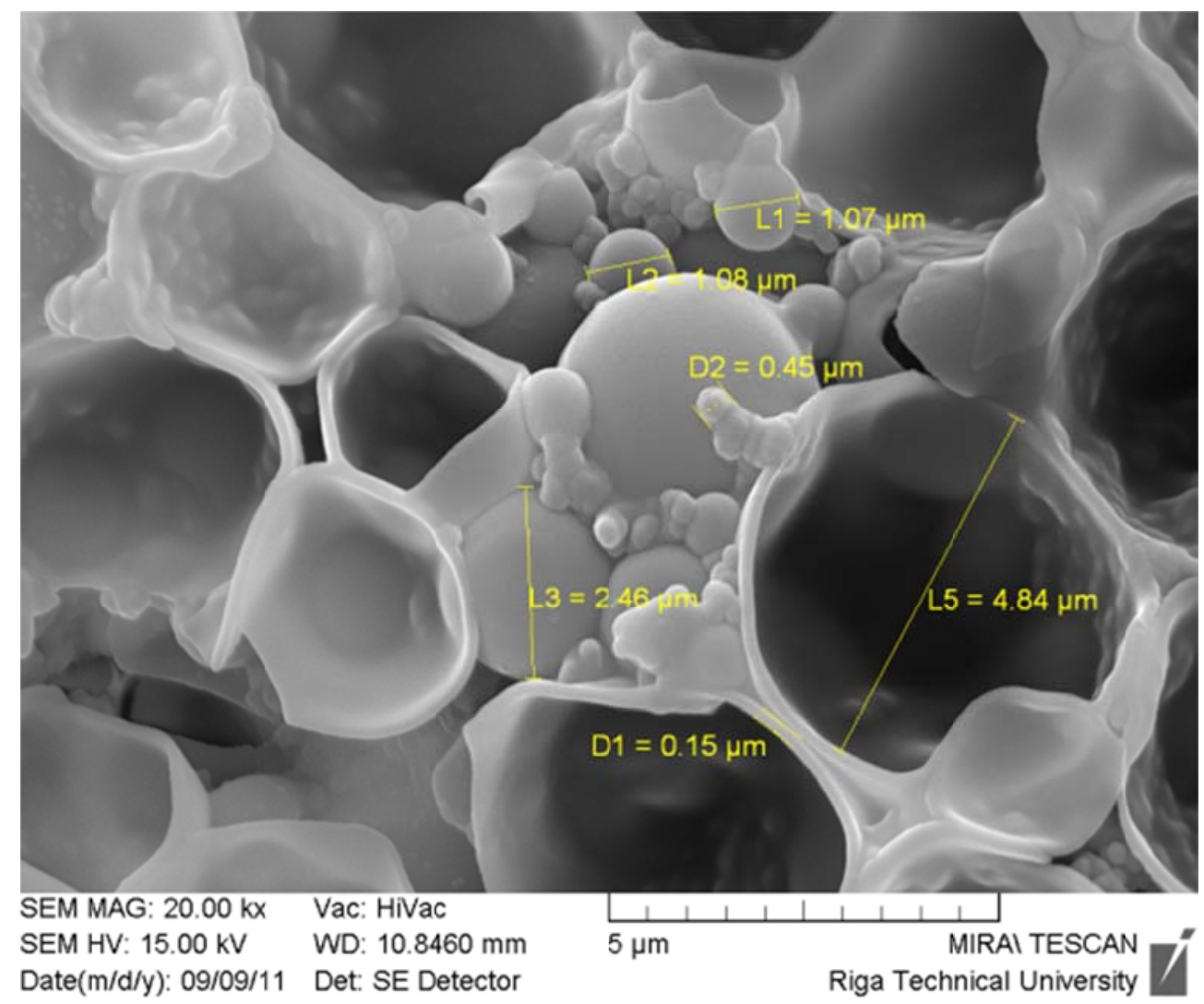

Figure 5. Shell thickness of PCM microcapsules [4].

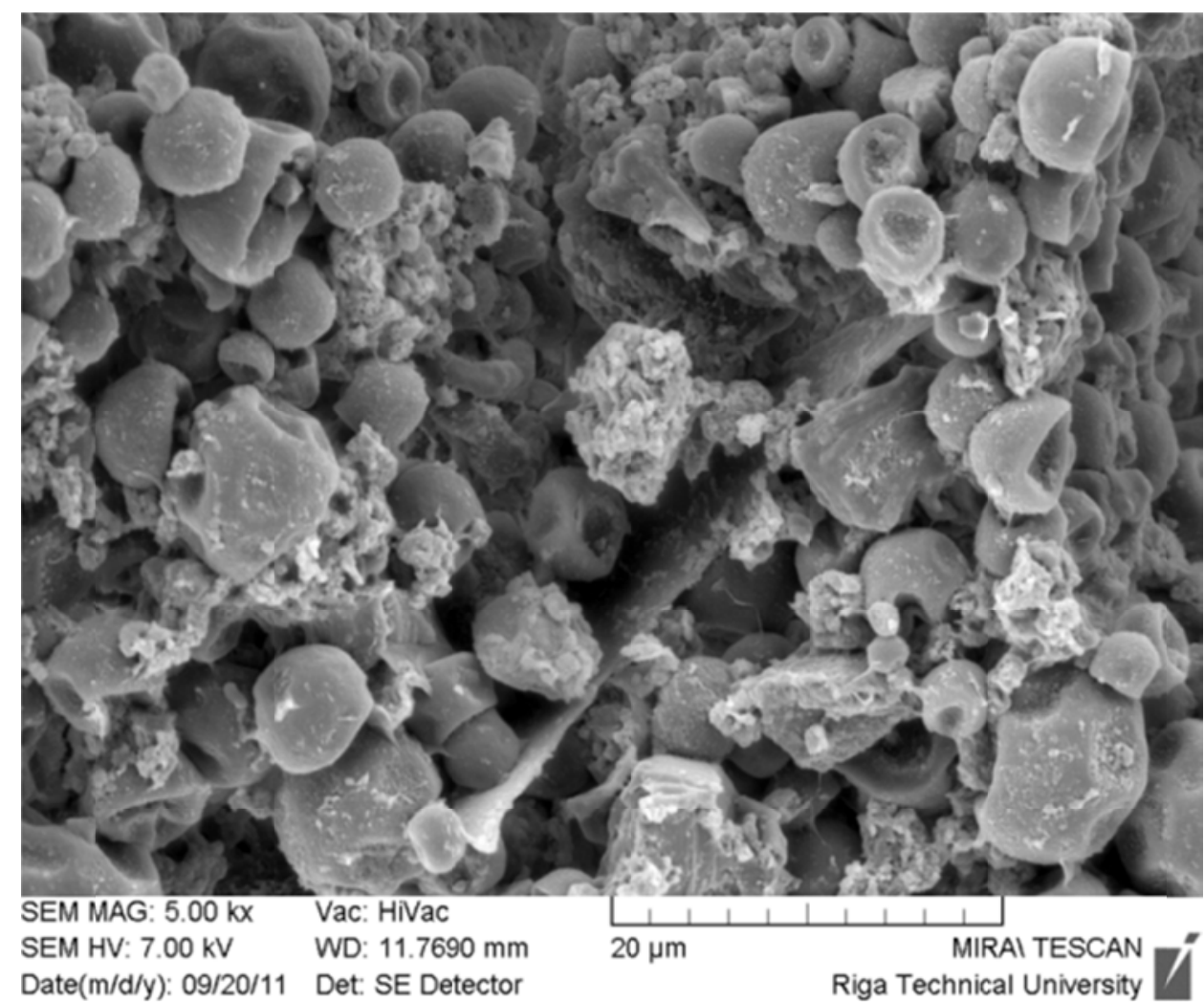

Figure 6. Microcapsules in the structure of composites [4]. 


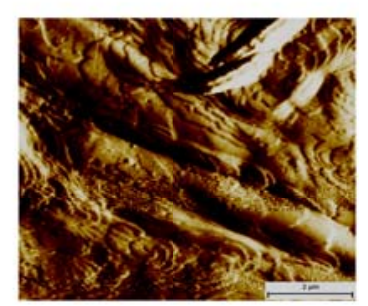

AFM phase image of $P 20-E$

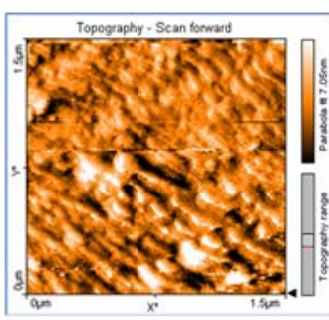

Phase image and Section profile cross the image of P15-E

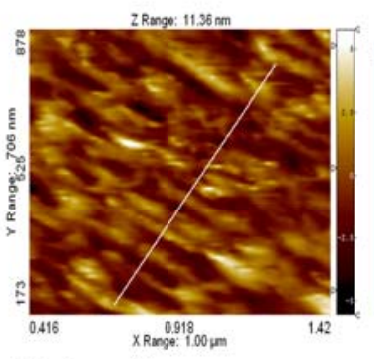

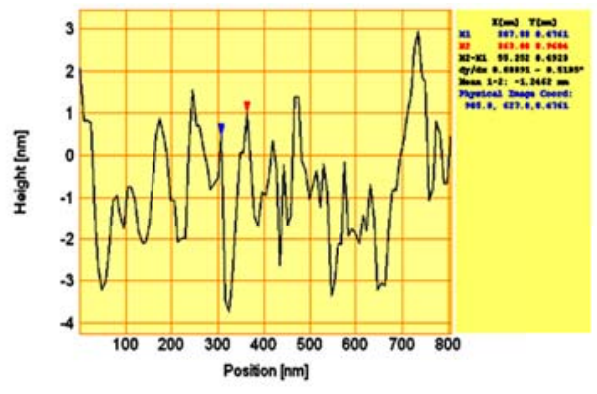

Physical image coordinates

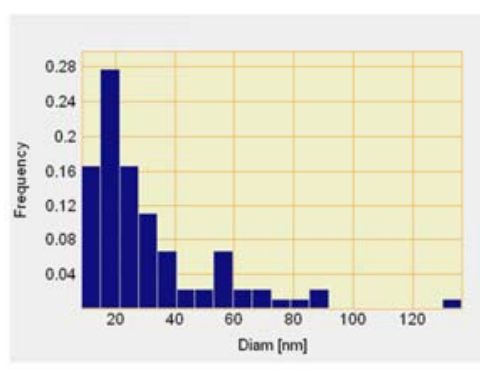

Lamellae width (thickness)

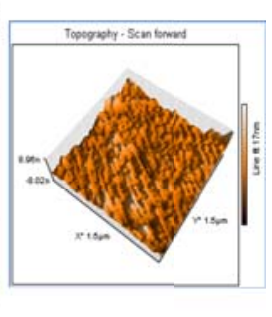

height image distribution

Figure 7. AFM of the PEG composites
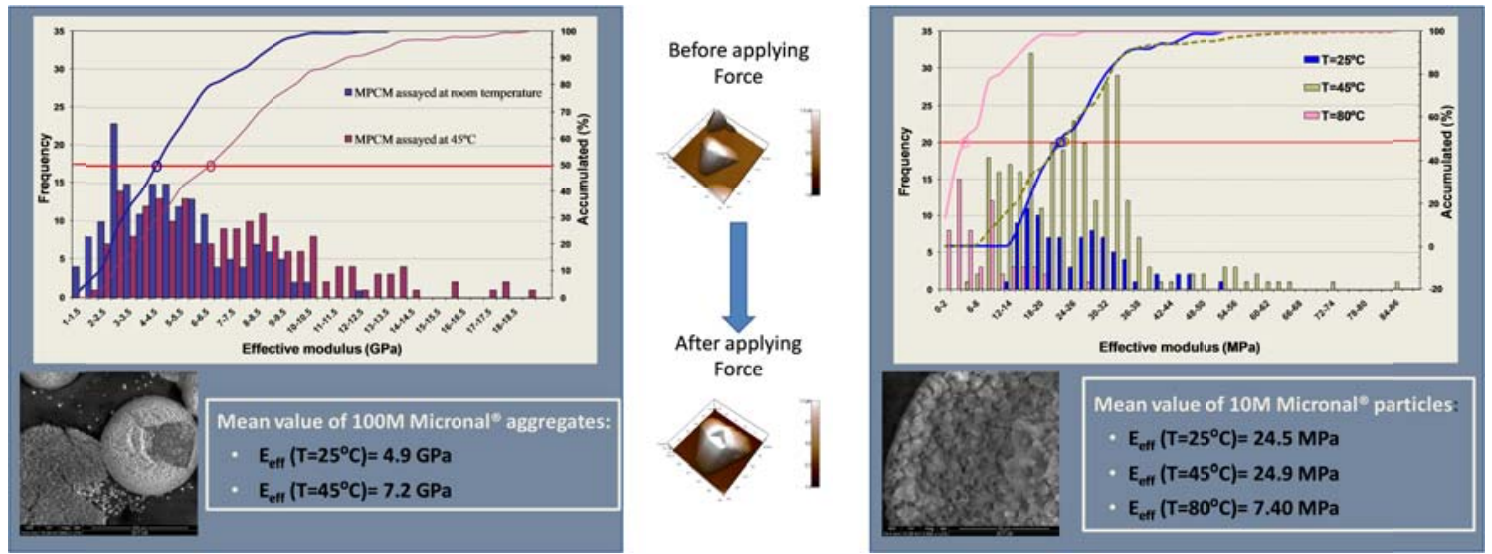

Figure 8. Statistical results of Micronal indentations with AFM [5]. 

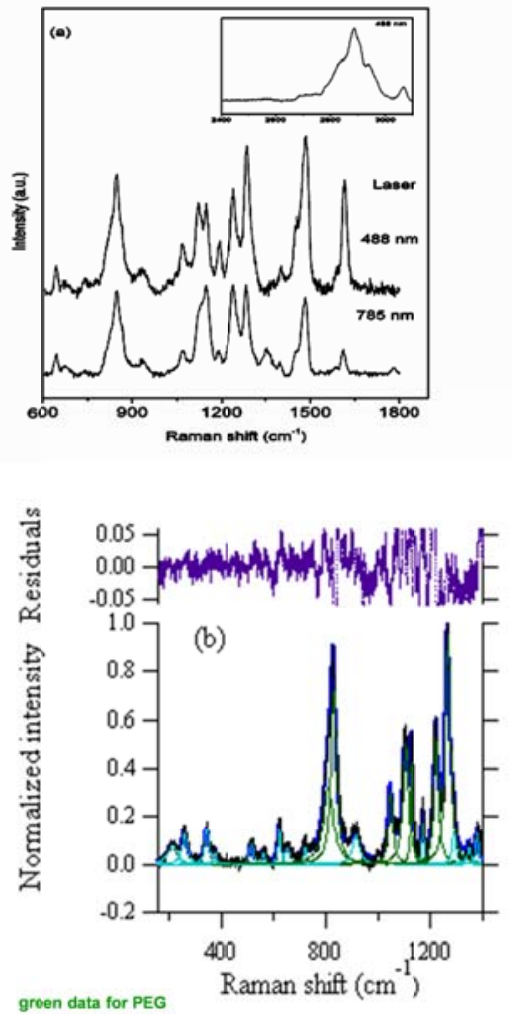

\section{Lorenzian deconvoluted Raman spectrum within $160-3200 \mathrm{~cm}-1$ at P15-E}

Results of the fitting procedure, assignments and literature data of the PEG 1500-epoxy(488 $\mathrm{nm}$ laser, room temperature)

\begin{tabular}{|c|c|c|c|c|}
\hline & $\begin{array}{l}\text { Peak } \\
\left(\mathrm{cm}^{-1}\right)\end{array}$ & $\begin{array}{l}\text { FWH } \\
\text { M }\end{array}$ & Assignment & $\begin{array}{l}\text { Literature } \\
\text { value }\left(\mathrm{cm}^{-1}\right)\end{array}$ \\
\hline 1 & 214.99 & 40.079 & & \\
\hline 2 & 261.26 & 22.78 & & \\
\hline 3 & 345.68 & 18.78 & & \\
\hline 4 & 375.26 & 15.145 & & \\
\hline 5 & 517.75 & 15.145 & & \\
\hline 6 & 563.23 & 15.145 & & \\
\hline 7 & 623.86 & 12.145 & & \\
\hline 8 & 655.34 & 20.292 & & \\
\hline 9 & 720.88 & 14.097 & & \\
\hline 10 & 810.43 & 44.536 & skeleton vibrations & 838 \\
\hline 11 & 830.63 & 24.268 & skeleton vibrations epoxide ring vibration & 8451123 \\
\hline 12 & 915.98 & 30.29 & epoxide ring vibration & 927 \\
\hline 13 & 1047.4 & 19.268 & stretching vibrations $\mathrm{COH}$ & 1057 \\
\hline 14 & 1104.7 & 25.024 & twisting vibrations of $\mathrm{CH}_{2}$ & 1118 \\
\hline 15 & 1128.9 & 10.268 & $\begin{array}{l}\text { twisting vibrations of } \mathrm{CH}_{2} \\
\text { bisphenol } \mathrm{A} \text { backbone vibrations }\end{array}$ & 11361123 \\
\hline 16 & 1172.6 & 8.0965 & bisphenol $\mathrm{A}$ backbone vibrations & 1196 \\
\hline
\end{tabular}

Figure 9. Raman spectra and band assignment for PEG composites [6].
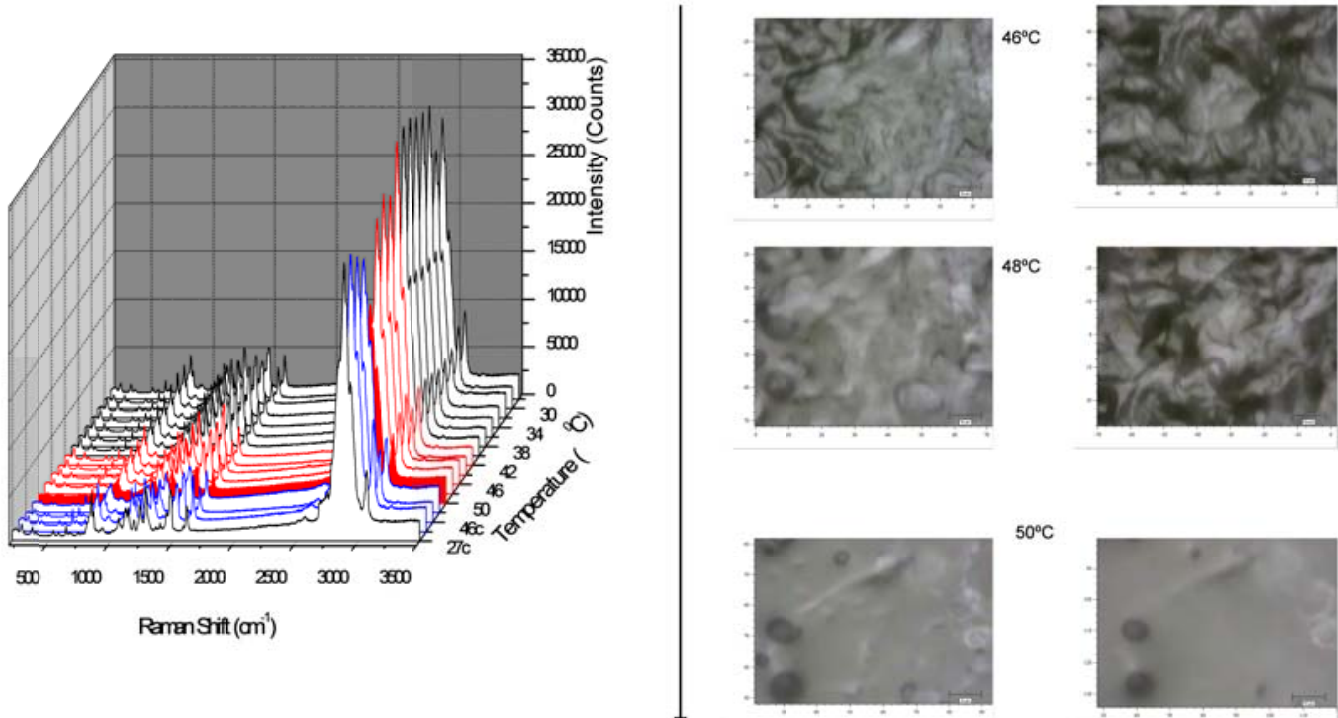

$50^{\circ} \mathrm{C}$

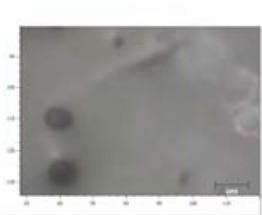

$50^{\circ} \mathrm{C}$

Figure 10. Raman Spectra and images inside a P15-E composite during phase change at cycling. 

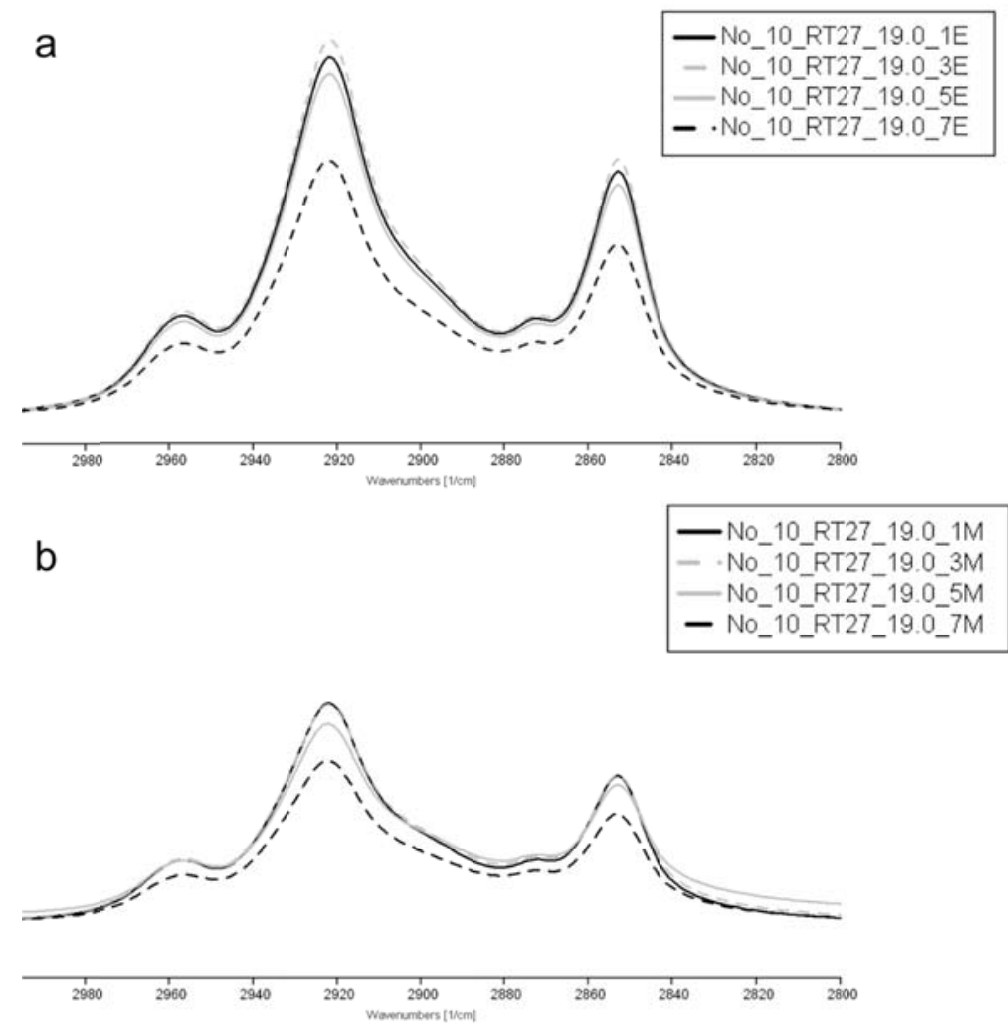

Figure 11. Variations of PCM concentration in sample: a - ATR-FTIR spectra of ends (E) of the sample; $b$ - ATR-FTIR of the middle of the samples (M) [7].

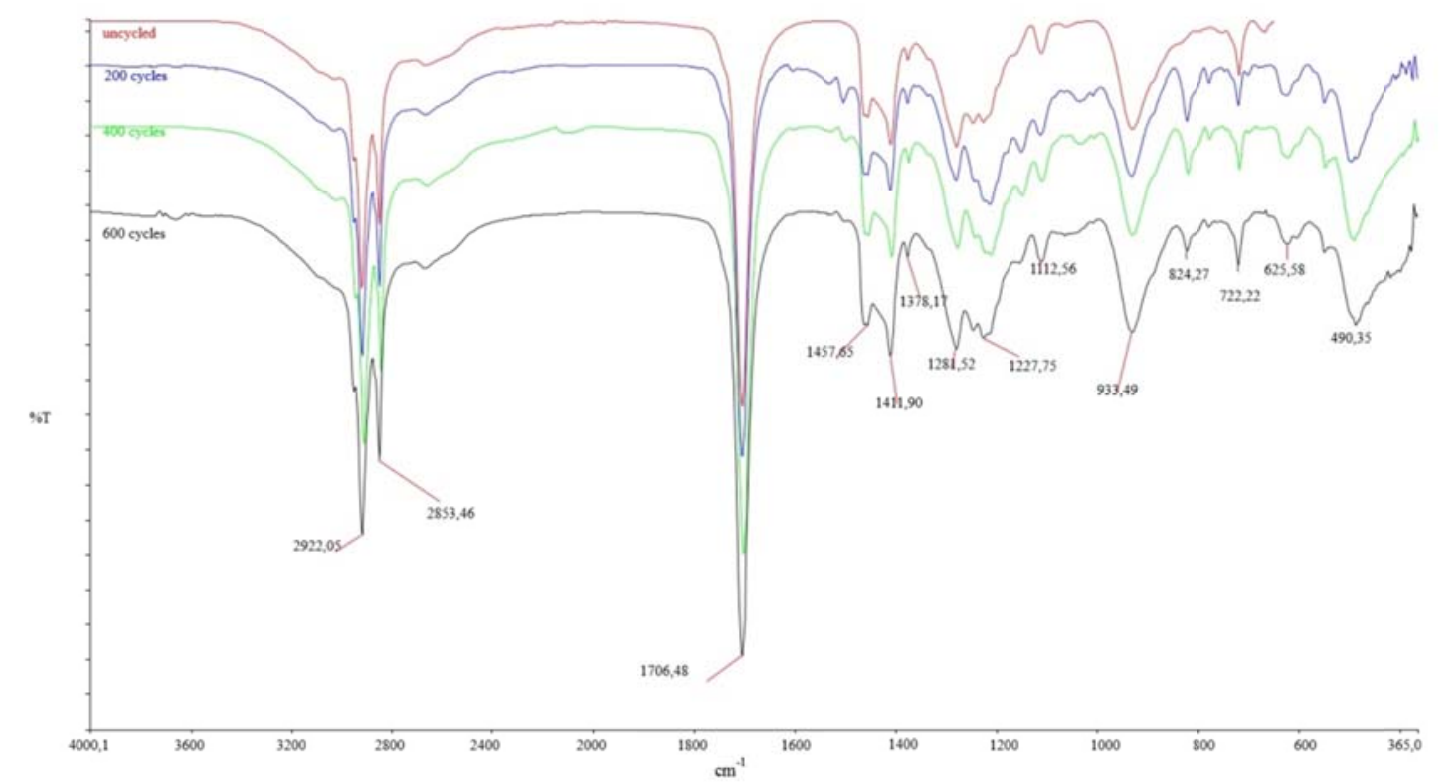

Figure 12. Comparison of FT-IR spectra of CA-MA binary mixture subjected to thermal cycles $(0,200,400$ and 600) [8]. 


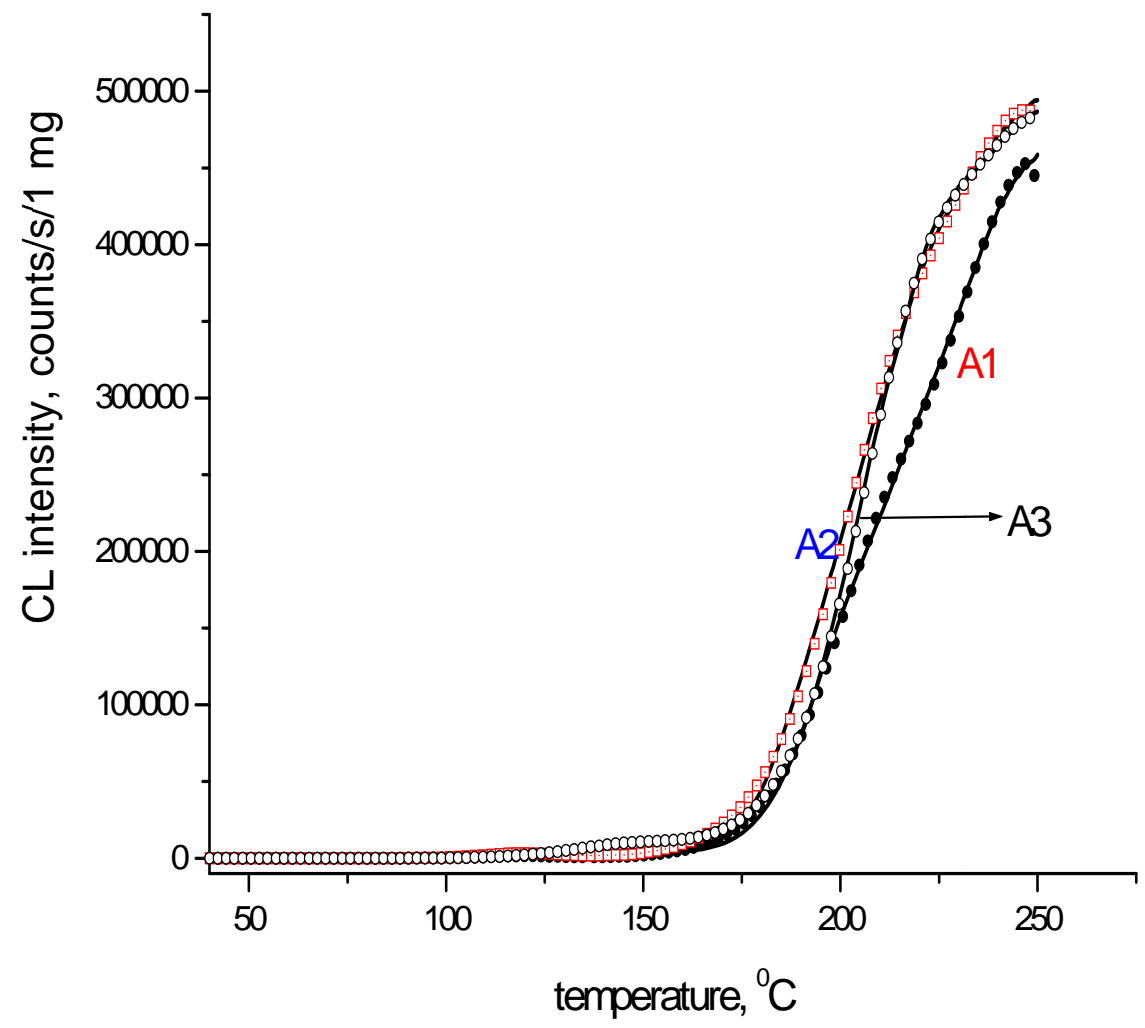

Figure 13. Modelling results of the dependence of chemiluminiscence with temperature (PEG composites)
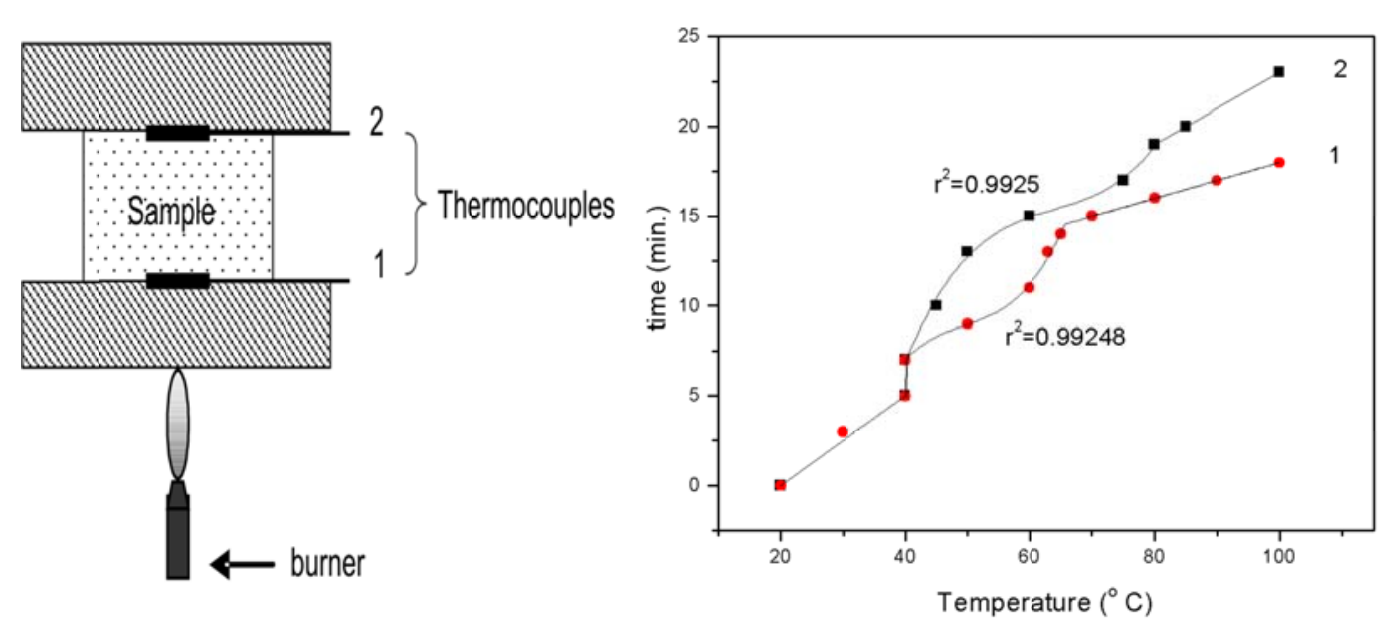

Figure 14. Left: Schematic representation of the experimental set-up for indirect fire retardation test.Right: Temperature evolution on the two sides of the test sample ( 1 and 2 define the two thermocouples in the left). 


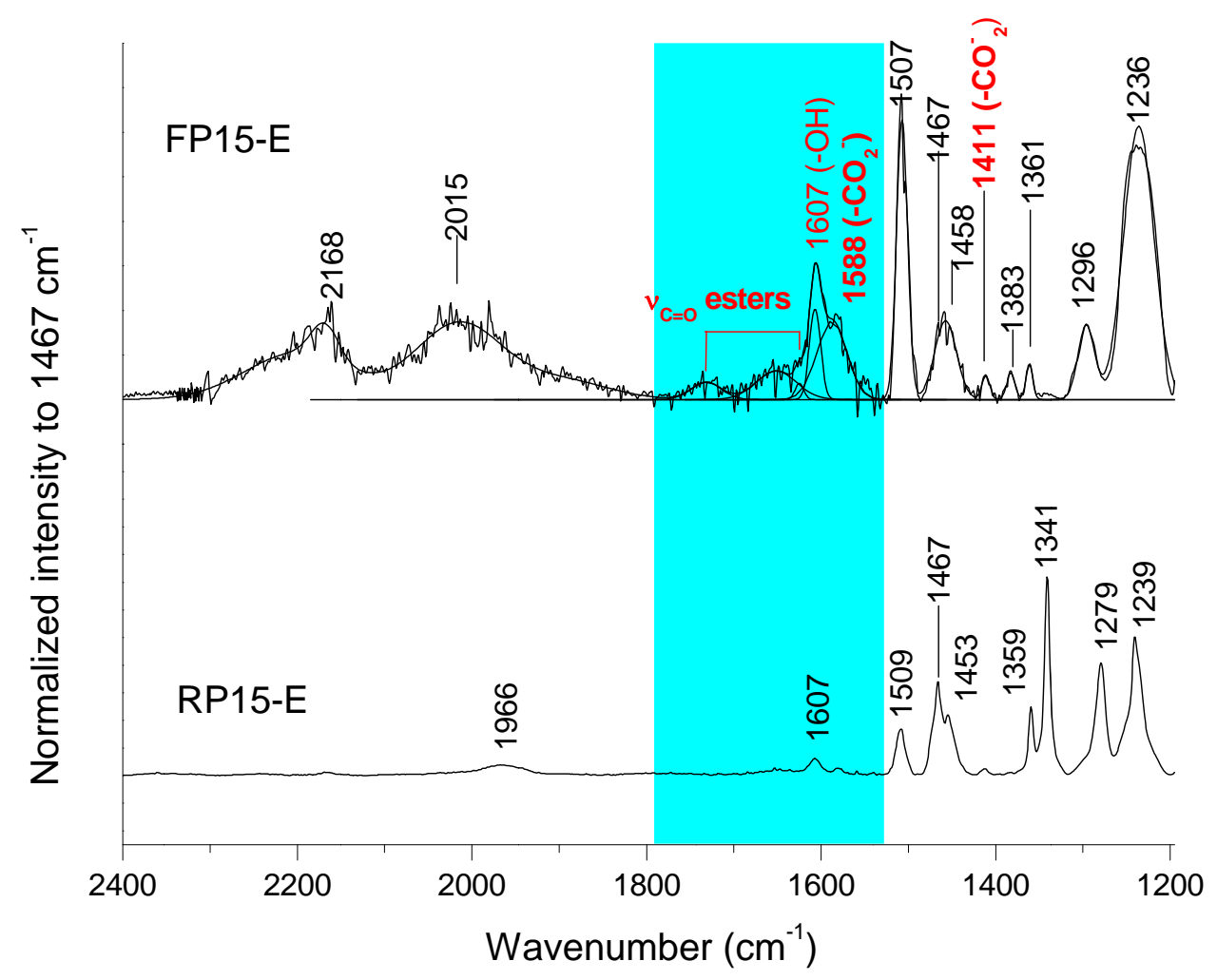

Figure 15. Gaussian fitted IR spectra of the RP15-E and FP15-E samples (turquoise area denotes $-\mathrm{COO}-,-\mathrm{OH}$ and $-\mathrm{CO}_{2}^{-}$modes), $1200-2400 \mathrm{~cm}^{-1}$ range.

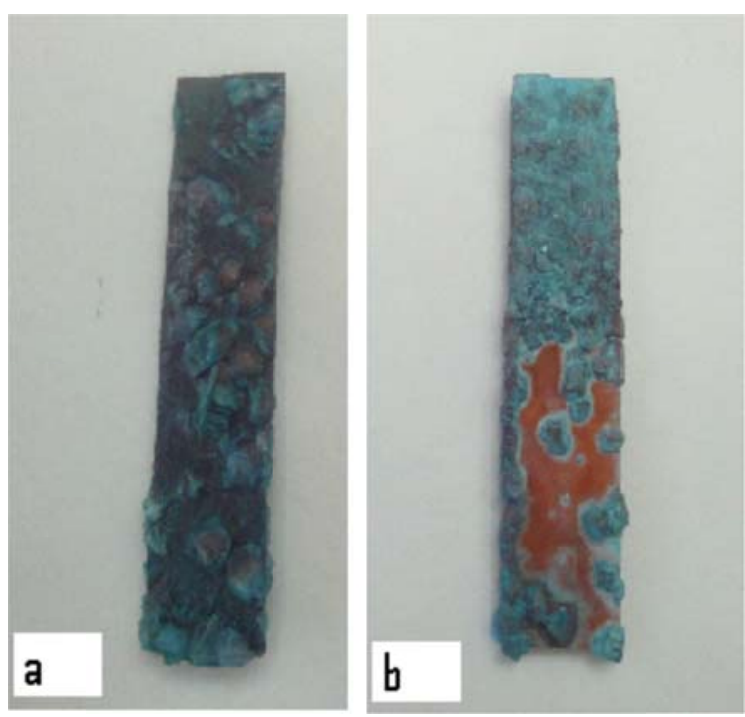

Figure 16. Formation of crystals on copper samples a) $19 \% \mathrm{NH} 4 \mathrm{Cl}+\mathrm{H} 2 \mathrm{O}$ and b) $19 \% \mathrm{NH} 4 \mathrm{Cl}+\mathrm{H} 2 \mathrm{O}+1 \% \mathrm{CMC}$. 


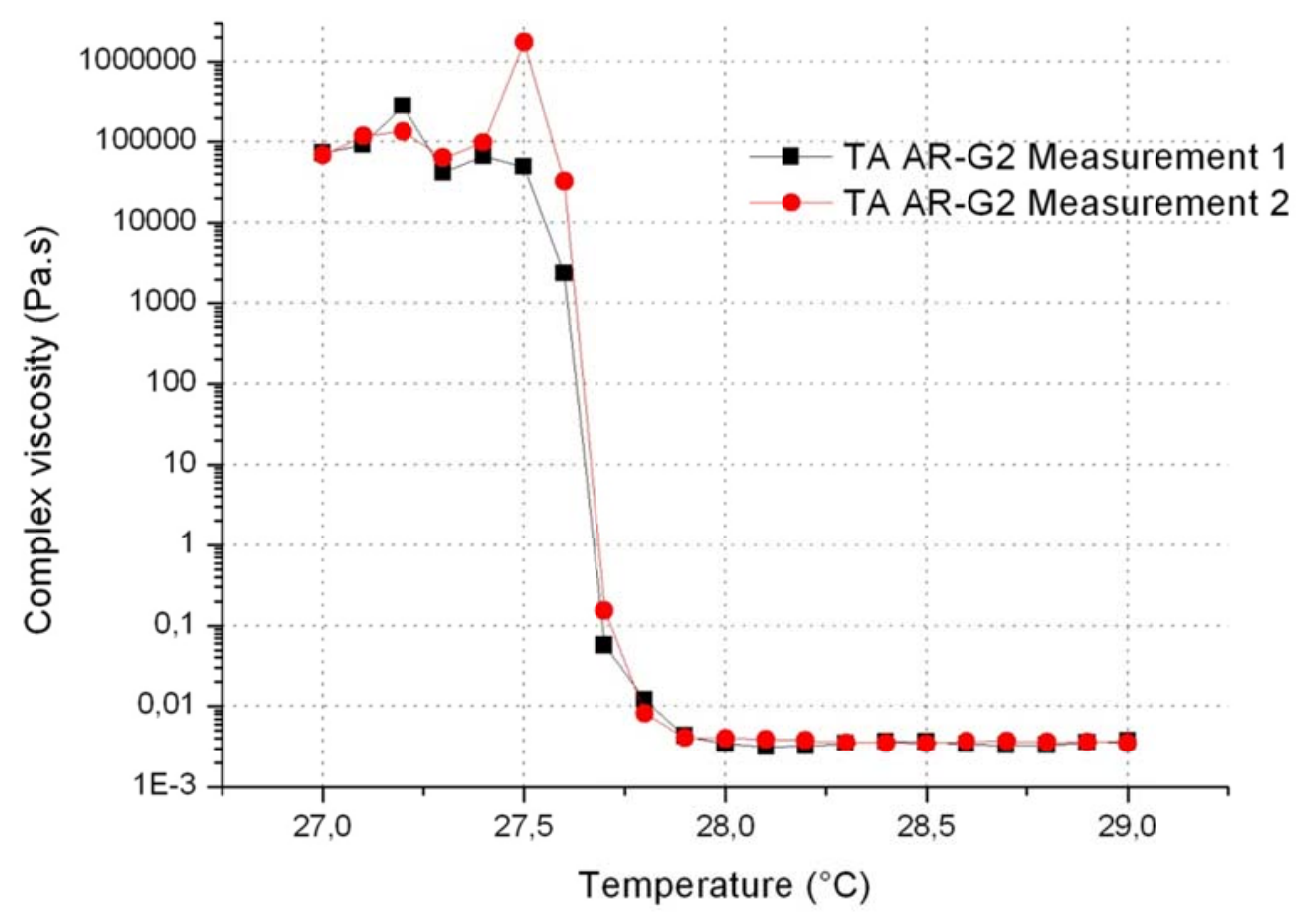

Figure 17. Examples of results of the rheological study of octadecane used as PCM [16].

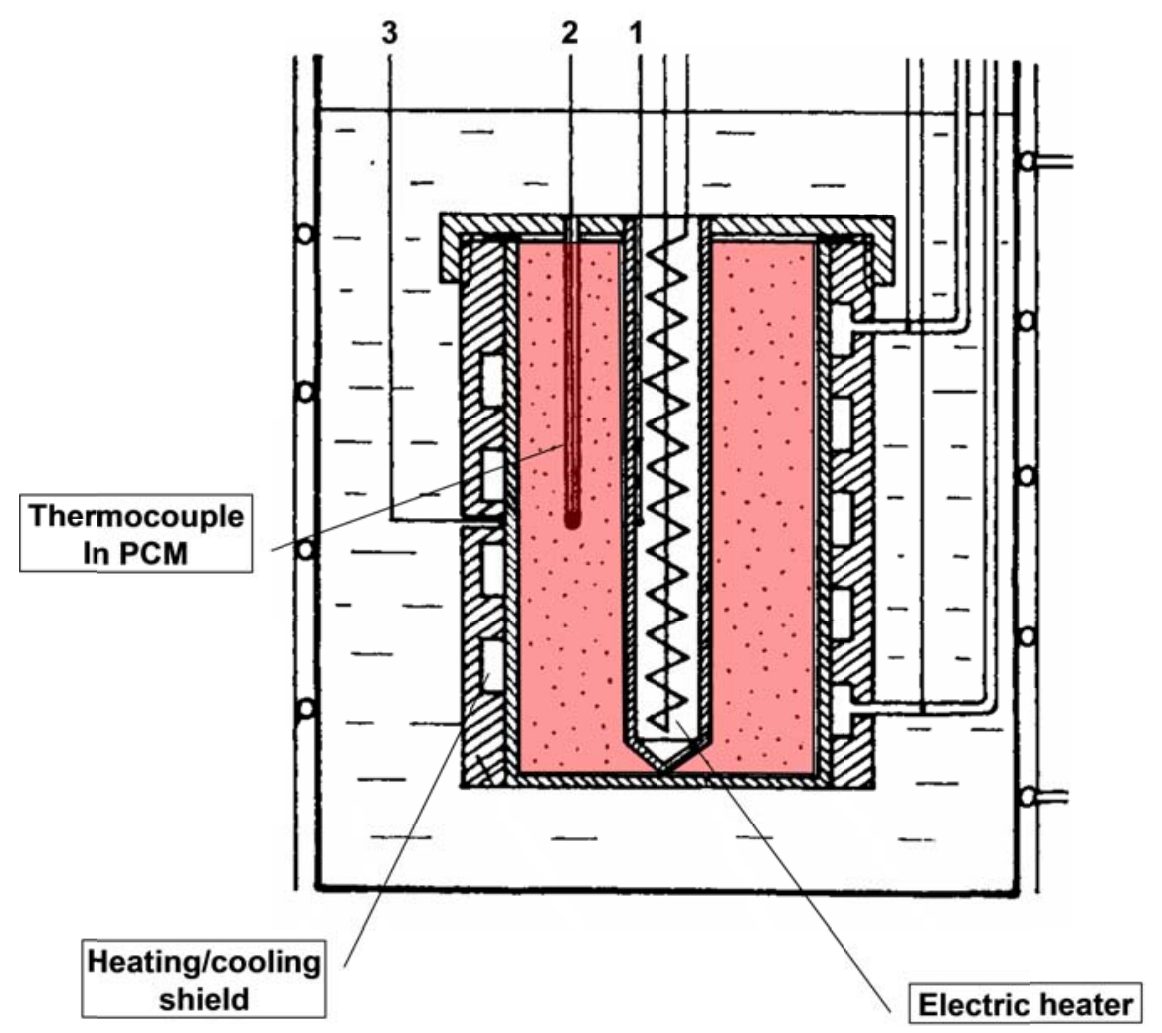

Figure 18. The scheme of the calorimeter for fast tests of the stability of thermal properties of PCMs during consecutive cycles of melting and solidification [17]. 

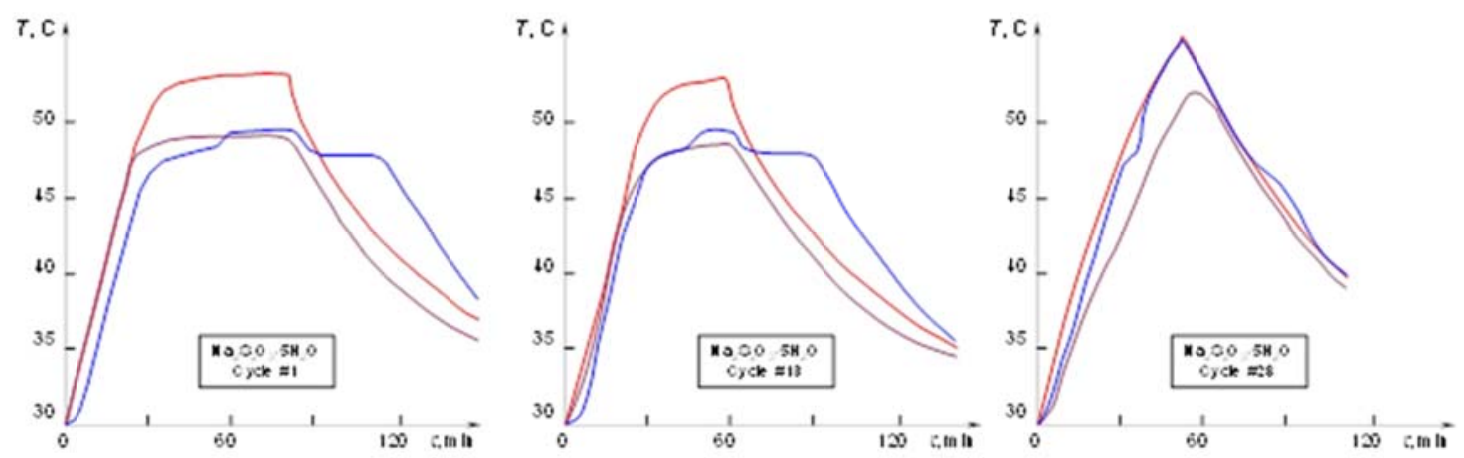

Figure 19. Temperature variation in selected points inside calorimeter (near heater, near cooling shield and inside material under investigation) during consecutive cycles of heating and cooling [17].
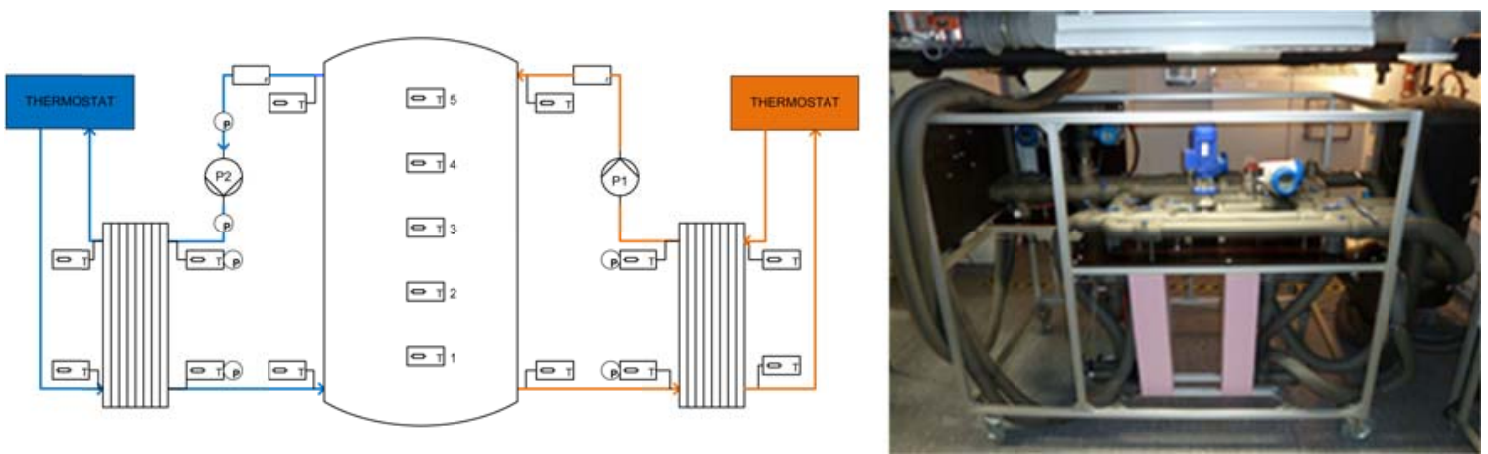

Figure 20. Test rig for PCS. Schematic drawing and photo of the system.
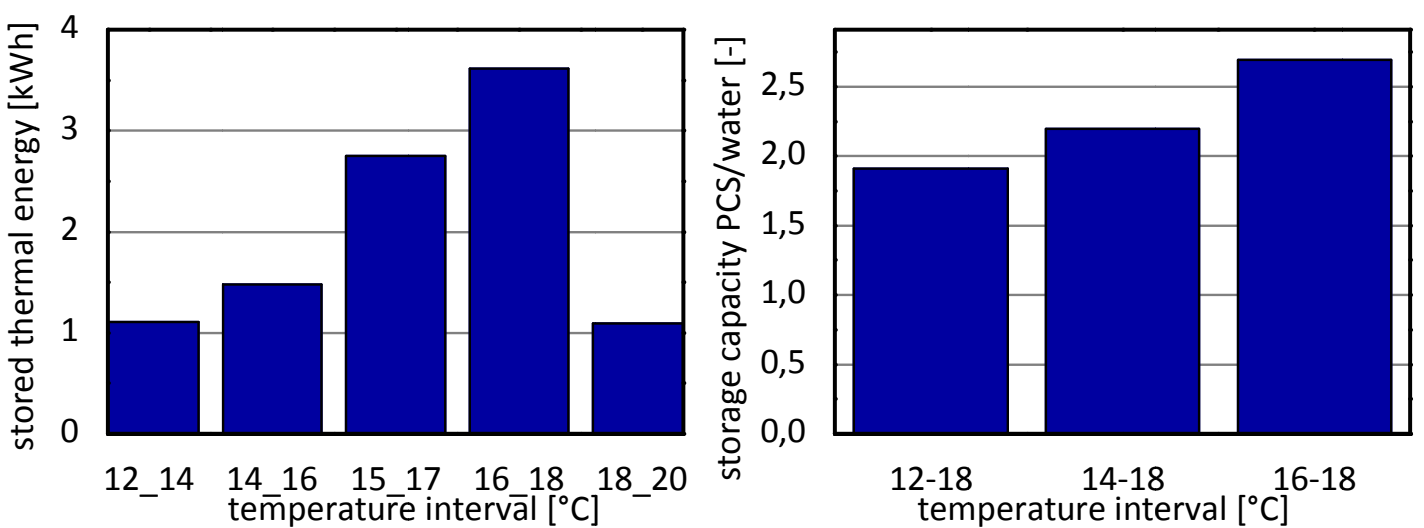

Figure 21. Stored heat operating the storage within $2 \mathrm{~K}$ temperature intervals (left) and wider temperature ranges (right). 


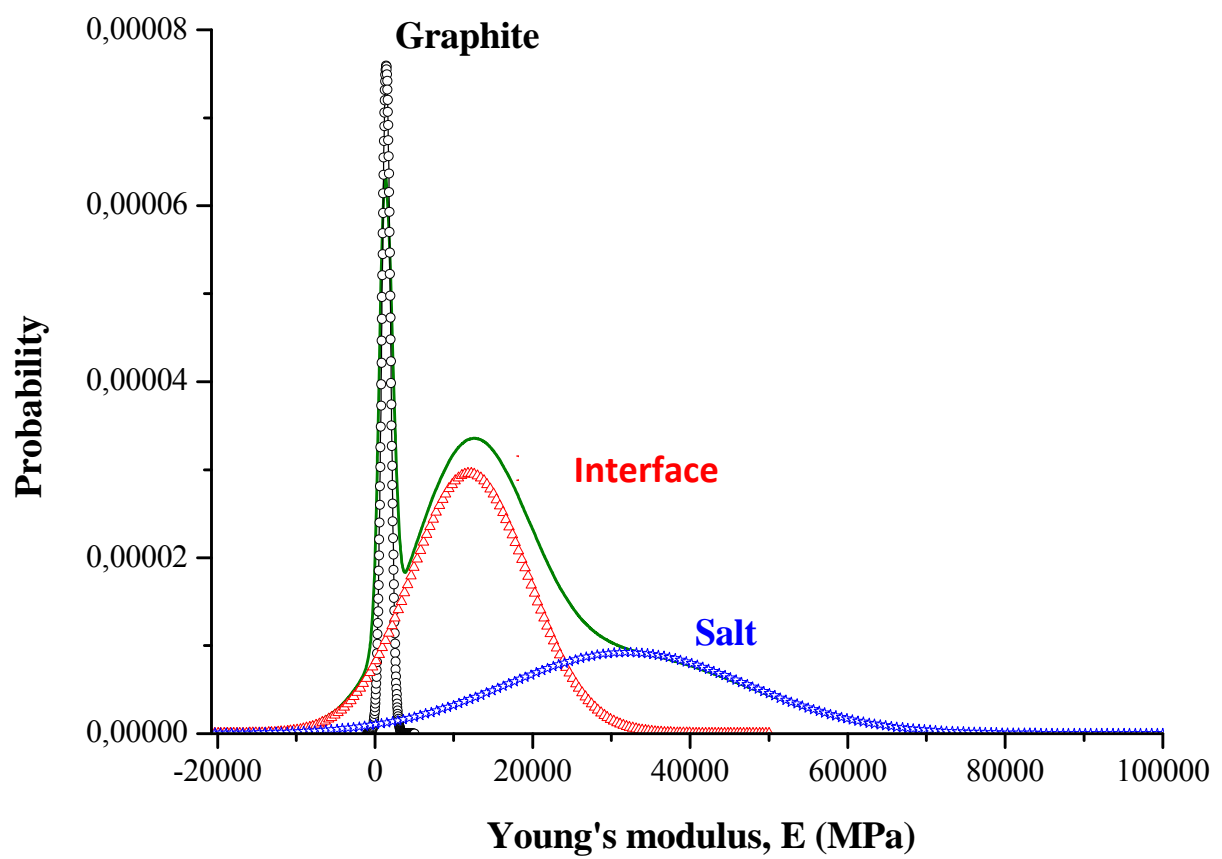

Figure 22. Young's modulus distribution simulated using the CDF fitting parameters for the D sample [18]. 